\title{
Plant Extracts and Reactive Oxygen Species as Two Counteracting Agents with Anti- and Pro-Obesity Properties
}

\author{
Hanna Zielinska-Blizniewska ${ }^{1}$, Przemyslaw Sitarek ${ }^{2}$, Anna Merecz-Sadowska ${ }^{3, *}$, \\ Katarzyna Malinowska ${ }^{1,3}$, Karolina Zajdel ${ }^{4}$, Marta Jablonska ${ }^{3}$, Tomasz Sliwinski ${ }^{5}$ and \\ Radoslaw Zajdel ${ }^{3}$ \\ 1 Department of Allergology and Respiratory Rehabilitation, Medical University of Lodz, 90-725 Lodz, Poland; \\ hanna.zielinska-blizniewska@umed.lodz.pl (H.Z.-B.); katarzyna.malinowska@umed.lodz.pl (K.M.) \\ 2 Department of Biology and Pharmaceutical Botany, Medical University of Lodz, 90-151 Lodz, Poland; \\ przemyslaw.sitarek@umed.lodz.pl \\ 3 Department of Economic Informatics, University of Lodz, 90-214 Lodz, Poland; \\ marta.jablonska@uni.lodz.pl (M.J.); radoslaw.zajdel@uni.lodz.pl (R.Z.) \\ 4 Department of Medical Informatics and Statistics, Medical University of Lodz, 90-645 Lodz, Poland; \\ karolina.smigiel@umed.lodz.pl \\ 5 Laboratory of Medical Genetics, Faculty of Environmental Protection, University of Lodz, 90-236 Lodz, \\ Poland; tomasz.sliwinski@biol.uni.lodz.pl \\ * Correspondence: anna.merecz-sadowska@uni.lodz.pl; Tel.: +48-6636-26667
}

Received: 30 August 2019; Accepted: 13 September 2019; Published: 14 September 2019

\begin{abstract}
Obesity is a complex disease of great public health significance worldwide: It entails several complications including diabetes mellitus type 2, cardiovascular dysfunction and hypertension, and its prevalence is increasing around the world. The pathogenesis of obesity is closely related to reactive oxygen species. The role of reactive oxygen species as regulatory factors in mitochondrial activity in obese subjects, molecules taking part in inflammation processes linked to excessive size and number of adipocytes, and as agents governing the energy balance in hypothalamus neurons has been examined. Phytotherapy is the traditional form of treating health problems using plant-derived medications. Some plant extracts are known to act as anti-obesity agents and have been screened in in vitro models based on the inhibition of lipid accumulation in 3T3-L1 cells and activity of pancreatic lipase methods and in in vivo high-fat diet-induced obesity rat/mouse models and human models. Plant products may be a good natural alternative for weight management and a source of numerous biologically-active chemicals, including antioxidant polyphenols that can counteract the oxidative stress associated with obesity. This review presents polyphenols as natural complementary therapy, and a good nutritional strategy, for treating obesity without serious side effects.
\end{abstract}

Keywords: obesity; plant extracts; polyphenols; reactive oxygen species

\section{Introduction}

Plant-based therapy and supplementation are common complementary treatments in various health problems. Several plant compounds may play a unique role in managing a number of diseases, and in vitro and in vivo studies have found some to exert positive effects against obesity. This effect has been attributed to the effects of numerous active compounds on the modulation of various signaling pathways. Thanks to their safety and extended efficacy, plant compounds are regarded as alternatives to traditional pharmaceuticals for treating obesity, or as the basis for the development of new pharmaceutical agents [1]. 
Despite being preventable, obesity is a growing, multifactorial disease afflicting both developed and developing countries. It is a serious problem for public health, and one that is associated with an increased rate of mortality, morbidity and decreased quality of life. It affects all age groups in populations including children, teenagers and adults. A 2016 WHO study [2] found overweight to affect 1.9 billion (39\%) adults worldwide and obesity 650 million (13\%); in addition, 41 million children aged under 5 and over 340 million aged 5 to 19 had a weight problem. The worldwide prevalence of obesity has nearly tripled since 1975 and if this trend continues, it is estimated that by 2030, 38\% of the population aged over 18 years will be overweight and $20 \%$ will be obese [3].

Obesity arises as a result of an energy surplus between calories consumed from food and those expended in metabolism and physical activity, with the correct energy balance being determined by genetic, epigenetic, and environmental factors. Overweight and obesity are most widely determined based on body mass index (BMI), is defined as weight $(\mathrm{kg})$ divided by height in meters squared (m). A BMI range of $18.5-24.9 \mathrm{~kg} / \mathrm{m}^{2}$ and $18.5-23 \mathrm{~kg} / \mathrm{m}^{2}$ is considered ideal, while overweight is defined as a BMI of 25 to 29.9 and 23 to $27.5 \mathrm{~kg} / \mathrm{m}^{2}$, and obesity of $\geq 30 \mathrm{~kg} / \mathrm{m}^{2}$ and $\geq 27.5 \mathrm{~kg} / \mathrm{m}^{2}$ for Caucasian and Asian population, respectively [4-7]. BMI tends to be higher among physically active individuals [8] and shorter adults [9] because may relate to increases in muscle mass and inverse BMI-height association, respectively. Additionally, BMI does not acquire body fat location information [10].

Obesity and overweight are defined as a condition of abnormal or excessive fat accumulation in adipose tissue resulting in impaired health. Both are associated with an elevated risk of various diseases, including type 2 diabetes, dyslipidemia, and cardiovascular diseases such as hypertension, stroke, and coronary heart disease. Overweight and obese people are also more subject to sleep apnea, cognitive dysfunction, nonalcoholic fatty liver disease, osteoarthritis, trauma and infection, and infertility. In addition, cancers such as endometrial, breast, prostate, colorectal, esophageal, renal cell, pancreatic, ovarian, thyroid, and gallbladder are also more prevalent [11-13].

Although the basis of obesity treatment remains a combination of dietary change and physical activity, this multifactorial, chronic disease requires a multifaced approach. Individuals who fail to respond to lifestyle modifications may require a different therapy; one such approach uses herbal medicine as supportive therapy. The present study reviews in vitro and in vivo studies of selected natural plant extracts believed to have anti-obesity potential and identify potential signaling pathways by which these active compounds may act.

\section{Reactive Oxygen Species (ROS) and Polyphenols as Two Opposing Pro and Anti-Obesity Factors}

ROS are molecules with an uncoupled electron that mediate cellular signal transduction. In living organisms, ROS are generated in the mitochondria, cytosol, peroxisomes, endoplasmic reticulum (ER), plasma membrane and lysosomes by various cellular systems [14], although most production occurs through the electron transport chain in mitochondria and nicotinamide adenine dinucleotide phosphate (NADPH) oxidases. ROS are divided into reactive oxygen radicals including superoxide $\left(\mathrm{O} 2^{\bullet-}\right)$, hydroxyl $\left({ }^{\bullet} \mathrm{OH}\right)$, peroxyl $\left(\mathrm{RO}^{\bullet}\right)$, alkoxyl $\left.(\mathrm{RO})^{\bullet}\right)$, and non-radicals such as hypochlorous acid $(\mathrm{HOCl})$, ozone $\left(\mathrm{O}^{3}\right)$, singlet oxygen $\left({ }^{1} \mathrm{O} 2\right)$, and hydrogen peroxide $\left(\mathrm{H}_{2} \mathrm{O}_{2}\right)$ that are converted into radicals [15]. While ROS play important roles in physiological cellular processes, their imbalance and excessive production leads to oxidative stress, followed by damage to biomolecules such as lipids, proteins, and DNA. To counter excessive oxidative stress, the human organism employs a range of antioxidants whose function is to scavenge ROS; these can be produced endogenously, such as superoxide dismutase (SOD), catalase (CAT), and glutathione peroxidase (GPX), or can be obtained exogenously, such as polyphenols [16]. ROS are involved in a number of processes in the human body, including the maintenance of the balance between mitochondria biogenesis and mitophagy, as well as the levels of inflammation, appetite, and energy homeostasis associated with obesity pathogenesis [17-19]. 
Bioactive compounds derived from plants may be biologically active natural products that exert positive health effects [20]. Despite the differences in their chemical structure, and their quantity and location in the plant, all have demonstrated considerable potential in therapies for various diseases, particularly regarding obesity. One of the most widespread groups of plant secondary metabolites is that of the polyphenols. Polyphenols range from simple chemical structures to highly-polymerized molecules, but all are based on a one or more aromatic ring which can be bound to one or more hydroxyl groups, or to other substituents such as methoxyl or carboxyl groups. More than 8000 polyphenols have been isolated from plants, half of which are flavonoids [21].

Polyphenols can be divided according to their chemical structures into phenolic acids, including (caffeic acid or chlorogenic acid), flavonoids, polyphenolic amides (avenanthramides, capsaicinoids) and other polyphenols (resveratrol, curcumin, rosmarinic acid, gingerol, ellagic acid, valoneic acid dilactone, secoisolariciresinol, and matairesinol). The flavonoids can be subdivided into isoflavones (genistein, daidzein), neoflavonoids (dalbergin), chalcones (phloretin, xanthohumol), flavones (apigenin, luteolin), flavonols (quercitin, kaempferol, myricetin), flavanones (hesperetin) and flavanonols (taxifolin), flavanols (catechins and gallocatechins), and proanthocyanidins (oligomeric procyanidins), anthocyanidins (cyanidin) [22]. These compounds in the plant play important roles including take part in metabolic processes, defense mechanisms, act as antimicrobial agents, serve as pigments to attract pollinators and to camouflage the plant itself [23-26].

Dietary polyphenol also plays a range of important roles in the human metabolism, in particular: antioxidant, anti-inflammatory, antibacterial, anti-cancer, and also anti-obesity effect related to its free radicals scavenging efficiency $[27,28]$.

Most interest in polyphenols is associated with their antioxidant properties known to counteract the effect of ROS and reactive nitrogen species on protein, lipid and DNAs, thus reducing the risk of cancer [29], diabetes mellitus [30] and its complications [31], inflammation [32], cardiovascular disease [33], and neurodegenerative disease [34]. They are known to significantly reduce the levels of ${ }^{\bullet} \mathrm{OH}, \mathrm{O}^{2} \bullet-, \mathrm{NO}^{\bullet}$, or $\mathrm{OONO}^{-}$by acting as electron or hydrogen atom donors and to prevent the formation of more reactive species by deactivating its precursor. Hydroxyl radical are probably the most known form of ROS; these are generated via multiple pathways, including peroxide reduction, mediated in vivo by either $\mathrm{Fe}^{2+}$ or $\mathrm{Cu}^{+}$metal ions via a Fenton-type reaction. The chelating properties of polyphenols reduce the rate of ${ }^{\bullet} \mathrm{OH}$ production by binding to transition metals such as $\mathrm{Fe}^{2+}[22,35]$. Additionally, the data indicated that polyphenols act also as co-antioxidants with essential vitamins, or their precursors, thus regenerating carotenoids [36] and vitamins $C$ and $E$ [37] and exerting synergistic antioxidant effects. In vitro studies suggest that polyphenols have the ability to inhibit lipoxygenases and cyclooxygenases prevents the release of arachidonic metabolites, an alternative source of non-mitochondrial ROS [38]. They are also able to increase the activity of potent antioxidant enzymes such as SOD, CAT, and GPX [39]. Antioxidant activity is correlated positively with the number of hydroxyl groups bound to the aromatic ring [40].

\section{The Impact of ROS on Mitochondrial Activity, the Inflammation Process, Hypothalamic Neurons, and Their Role in Obesity}

\subsection{Mitochondrial Activity in Obese Subjects}

Mitochondria play central roles in ATP production, and in eukaryotic cells, the major source of ROS is the mitochondrial respiratory chain during the course of ATP production. Excess levels of nutrients results in abnormalities in mitochondrial number, dynamics, and morphology, as well as defects in biogenesis, ROS production and apoptosis. In adipocytes, mitochondrial dysfunction is closely related to metabolic disorders including altered adipogenesis, lipolysis, fatty acid esterification, and adiponectin production, as well as harmful effects of excessive ROS [41]. In obese individuals, mitochondria show less efficient energy generation and reduced fatty acid oxidation [42], abnormal lipid and glucose metabolism [43] and increased susceptibility to apoptosis [44]. An increase in glucose levels results in increased ROS production, which may damage mitochondrial enzymes and 
other proteins. In addition, the disruption of the uptake and storage of nutrients, together with the insulin signaling pathway managing the accumulation of lipids and free fatty acids leads to the development of metabolic disorders [41]. Furthermore, transcriptional activation of fatty acid biosynthesis and metabolic reprogramming to glycolysis caused by mitochondrial abnormalities and decreased mitochondrial DNA result in significantly greater formation of lipid droplets [45]. Damaged mitochondria can be removed via a process called mitophagy [46] and replaced by new ones through another process closely linked to ROS production [47]. The upregulation of mitochondrial functions in obesity is associated with metabolic alterations, low-grade inflammation [48] and dysregulated responses of the hypothalamic neurons controlling energy homeostasis to changes in glucose level [49].

\subsection{Chronic Low-Grade Inflammation as a Result of Increased Adipocyte Number}

Obesity is associated with chronic inflammation process. Adipose tissue not only stores fat but also plays a cell regulatory function using a complex network of endo, para and autocrine signals that influence the immune system response, among others. Adipocytes secrete several molecules, such as hormones, growth factors, enzymes, cytokines, complement factors and matrix proteins [50]. The anti- and pro-inflammatory proteins secreted from adipose tissue are called adipocytokines. Of these, adiponectin, transforming growth factor beta (TGF $\beta$ ), interleukin (IL)-IL-10, IL-4, IL-13, and IL-1 receptor antagonist (IL-1Ra), and apelin are anti-inflammatory, whereas tumor necrosis factor- $\alpha$ (TNF- $\alpha)$, IL-6, leptin, visfatin, resistin, angiotensin II, and plasminogen activator inhibitor 1 are proinflammatory. The anti-inflammatory proteins mediate physiological functions while the proinflammatory ones stimulate inflammatory pathways [51]. In cases of obesity, the number and size of the adipocytes are increased, together with the secretion of various pro-inflammatory molecules, thus enhancing the pathological state [52].

Adipogenesis is a complex process in a series of stages by with differentiation of precursor cells, mainly stem cells-derived, to mature adipocytes is mediated by numerous transcription factors, cell-cycle proteins, hormones, and small molecules. Potential redox-sensitive regulation of that pathways is mediated by receptor tyrosine kinases, peroxisome proliferator-activated receptor $\gamma($ PPAR $\gamma)$, PPAR $\gamma$ coactivator $1 \alpha$ (PGC- $1 \alpha)$, AMP-activated protein kinase (AMPK), and CCAAT/enhancer binding protein $\beta$ (C/EBP $\beta)$ [53]. In general, the studies indicate that ROS are involve in signal transduction and regulation of adipocytes differentiation, but the precise role remain unclear. NADPH oxidase is a crucial source of ROS in preadipocytes [54]. Activated insulin-like growth factor (IGF) receptor is a tyrosine kinase responsible for activation of downstream signaling pathways such as phosphatidylinositol 3-kinase (PI 3-kinase) and Ras-mitogen-activated protein kinase (MAPK) pathway [55]. ROS regulate MAPK activation, major regulator in cell growth and differentiation via oxidative modifications of important signaling proteins and inactivation of MAPK phosphatases [56]. PPAR $\gamma$ is a central regulator of adipogenesis [57] and there is an evidence that Cys285, located in the ligand-binding domain is redox-sensitive [58]. Another adipogenesis-related redox-sensitive signaling molecule is $\mathrm{C} / \mathrm{EBP} \beta$, also taking part in that process as important regulator. It has been shown that ROS induce disulfide bond formation between Cys296 and Cys143 followed by dimerization of that transcription factor, additionally potentiating its activity [59]. Additionally, oxidative stress is related to increase expression of PPAR $\gamma, \mathrm{C} / \mathrm{EBP} \beta$ [60], and PGC- $1 \alpha$ molecules. Therefore, redox imbalance in fat tissue may lead to abnormal mechanisms of adipocyte differentiation and its dysfunction in obesity.

Inflammation is considered as a collection of protective mechanisms developing in response to various factors, such as tissue damage, pathogens, harmful chemical and physical stimuli. Proinflammatory agents activate appropriate receptors and trigger intracellular signaling pathways, such as the mitogen-activated protein kinase (MAPK), nuclear factor kappa-B (NF- $\mathrm{kB}$ ), and Janus kinase (JAK)-signal transducer, and activator of transcription (STAT) pathways. Two types of inflammatory responses are distinguished: acute or chronic. Acute immune response is terminated after the elimination of the causative agent and the restoration of homeostasis, while chronic inflammation persists for a longer period of time and can be caused by factors that cannot be eliminated [61]. 
The alternation of immunity as a result of the excess proinflammatory agents generated in cases of obesity is known as chronic low-grade inflammation [52]. This inflammation is associated with various complications, including cardiovascular disease, diabetes mellitus, and cancer [62]. Although the precise relationship between obesity and inflammation is unclear, the strong link is known to exist between inflammation and ROS [63].

A high-fat diet plays an important role in inflammation of the intestine, which is observed during obesity. Overweight people are characterized by different gut microbiome profiles to those of normal weight [64], with the share of Gram-positive bacterial species tending to grow, resulting in higher levels of lipopolysaccharide (LPS) circulating in the intestine. These LPS are able to activate Toll-like receptors (TLR), resulting in the activation of the myeloid differentiation (MyD)-88 factor, tumor necrosis factor receptor-associated factor (TRAF)-6, IL1R-associated kinases (IRAK1, IRAK4) and the IkB kinase complex. That proteins activates various signaling cascades, including the transcription factors NF- $\mathrm{kB}$, extracellular signal-regulated kinase (ERK), MAPK and c-Jun $N$-terminal kinase (JNK), resulting in the stimulation of the production of inflammatory cytokines, chemokines, and adhesion molecules [65]. Saturated fatty acids are the other ligands for the TLR4 receptors [66], that do not directly bind but through fetuin A [67] or production of danger-associated molecular patterns (DAMPs) [68] and ceramides [69].

ROS are also able to activate NF- $\mathrm{KB}$ signaling pathways. Hydrogen peroxide $\left(\mathrm{H}_{2} \mathrm{O}_{2}\right)$ affects the degradation of $I \kappa B \alpha$, an NF- $\kappa B$ inhibitor, through tyrosine phosphorylation [70]. After DNA binding, numerous enzymes are activated, including NADPH oxidase, cyclooxygenase-2, and arachidonate 5and 12-lipoxygenases; this potentiates ROS overproduction or releasing nitric oxide synthases and producing reactive nitrogen species in cells potentiates ROS-induced damage [71]. The presence of ROS upregulates the expression of TLR2 and 4, their related metabolic regulators IRF3 and IRF5, and their signature proinflammatory cytokines in human peripheral blood mononuclear cells via MAPK/NF- $\mathrm{B}$ pathways [72]. Excess nutrition oversupplies skeletal muscle cells and induces NF- $\mathrm{kB}$ signaling pathways; this results in overproduction of ROS by interfering with mitochondrial function [73].

Inflammasomes are innate immune system receptors and sensors that induce inflammation in response to pathogenic microorganisms and sterile stressors. They contain the nucleotide-binding domain leucine-rich repeat (NLR) protein, the apoptosis-associated speck-like protein containing a CARD adaptor protein (ASC) and caspase- 1 . After the formation of the protein complex, caspase 1 activate following the pro-inflammatory cytokines such as IL-1 $\beta$ and IL-18. Overexpression of NLR family pyrin domain containing 3 (NLRP3) and caspase- 1 has been identified in obese mice [74] and human subjects [75]. ROS is essential for activation of inflammasome. A two-step mechanism has been proposed for the induction of NLRP3 inflammasomes in macrophages. The first is triggered by microbial or endogenous molecules, resulting in upregulation of that complex and pro-IL-1 $\beta$ expression via NF- $\mathrm{KB}$ induction [76]. The second is based on signals from numerous different pathways including ion fluxes, lysosomal destabilization, post-translational modifications of NLRP3 and ROS production. $\mathrm{K}^{+}$efflux is initiated by several activators such as ATP and particulate molecules. Accumulation of unsaturated fatty acids, characteristic of obesity, contribute to membrane decomposition followed by their disruption and NLRP3 activation via $\mathrm{K}^{+}$efflux [77]. The endoplasmic reticulum (ER) releases high levels of $\mathrm{Ca}^{2+}$ from storage, resulting in mitochondrial dysfunction and the production of mitochondrial ROS. Additionally, $\mathrm{Na}^{+}$influx and $\mathrm{Cl}^{-}$efflux are also reported as important stimuli for the activation of the NLRP3 inflammasome. Also various activators, such as particulate matter, activate the NLRP3 inflammasome through lysosomal destabilization by inducing lysosomal rupture and cathepsin $\mathrm{B}$ release. This process can run in relation to $\mathrm{K}^{+}$efflux.

Two very common post-translational modifications of NLRP3, viz. phosphorylation and ubiquitination, may also predispose the NLRP3 inflammasome for activation. One of the first identified NLRP3 inflammasome activation agents are ROS [78]. A high fat diet and excess levels of fatty acids can also induce inflammasome in an AMP-activated protein kinase (AMPK)-autophagy-ROS-dependent 
manner [79]. The details of how this activation proceeds are unclear but one of the components of the inflammasome complex, NIMA-related kinase 7 (NEK7), may act as a ROS sensor [80].

The ER plays an important role in the storage of glucose, protein, lipid metabolism, and calcium ions, and regulates several cellular processes, including inflammation and nutrient metabolism, via the unfolded protein response (UPR) signaling pathway. In numerous tissues and cell types, UPR activation may occur as a result of increased levels of free fatty acids, particularly saturated fatty acids. Moreover, UPR may by activated by changes in the lipid composition of the ER; this can lead to impairments in the activity of the sarco-/endoplasmic reticulum calcium ATPase followed by an imbalance in homeostasis. UPR may be also direct activated by three proteins localized in the ER: double-stranded RNA-dependent protein kinase-like ER kinase (PERK), inositol-requiring $1 \alpha$ (IRE1 $\alpha$ ) and, possibly, activating transcription factor- $6 \alpha$ (ATF6 $\alpha$ ) [81]. UPR activation results in the activation of proinflammatory genes, including those encoding TNF- $\alpha$, IL-1 $\beta$, IL-6, IL-12p40, and cyclooxygenase-2 by primarily activating NF- $\mathrm{kB}$, an important transcription factor of M1 macrophages [82,83]. The NF- $\mathrm{KB}$ signaling pathway also regulates the activity of inflammasomes and induces transcriptional expression of NLRP3 [84].

Many reactions housed within the ER generate ROS, particularly ER chaperones and oxidoreductases. Protein disulphide isomerase (PDI) is a multifunctional redox chaperone. PDI catalyzes disulphide bond formation via an isomerization process associated with sequential oxidation and reduction reactions: the mobile arm of PDI opens when oxidized and closes when reduced; the catalytic cycle is then completed by re-oxidation of PDI. The final re-oxidation is performed by several proteins, including flavin adenine dinucleotide (FAD) binding oxidases, oxidized glutathione, glutathione peroxidase 7 and 8, quiescin sulfhydryl oxidase and also protein endoplasmic reticulum oxidoreductin-1 (Ero1); these take part in an oxygen reduction reaction to produce $\mathrm{H}_{2} \mathrm{O}_{2}$. One mechanism of stress-related ROS induction by the ER involving PDI induction helps prevent protein misfolding [85-87]. In a study of 3T3-L1 adipocytes in mice fed a high-fat diet for 16 weeks, ER stress was found to be induced by ROS generation mediated by free fatty acids and excessive expression of inflammatory cytokines [88].

Macrophages play an important role in the inflammatory process. Various mechanisms allow the infiltration of immune cells into obese adipose tissue, including adipocyte death, chemotactic regulation, hypoxia, and fatty acids flux [89]. The macrophage population is divided into activated macrophages (M1) and alternatively activated macrophages (M2). The M1 group is activated by interferon- $\gamma$ alone or in combination with microbial stimuli or cytokines; it takes part in Thelper type 1 (Th1) responses responsible for organ-specific autoimmune disorders. In contrast, the M2 group takes part in tissue remodeling, thus participating in the angiogenesis associated with tumor progression. M2 is activated by IL-4, IL-10, IL13, and IL-33. While M1 is a pro-inflammatory group that releases TNF- $\alpha$, IL-1 $\beta$, IL-12, and IL-23 upon stimulation whereas M2 is an anti-inflammatory group that secretes IL-10 and TGF- $\beta$ [90-92]. Obesity state is characterized by a change of macrophage phenotype from M2 to M1, which propagates inflammatory cascades [93].

It has also been suggested that adipose tissue exhibits a hypoxic phenotype due to impairment of oxygen delivery [94]. It has been found in obese mice that the inflammatory M1 polarity of macrophages is activated by hypoxia-related genes in an hypoxia-inducible factor 1-alpha (HIF-1 $\alpha$ )-dependent or independent manner [95]. The presence of ROS promotes the proinflammatory M1 phenotype; M1 macrophage activation is correlated with dysregulation of the TNF $\alpha$ mediated inflammatory response. The binding of TNF $\alpha$ to the receptor initiates signaling cascades, including MAPK [96] and the IкB (IKK) kinase through NF-KB signaling pathway activation [97]. TNF- $\alpha$ increases ROS production by activating $\mathrm{NAD}(\mathrm{P}) \mathrm{H}$ oxidase, which releases $\mathrm{O}^{2-}$ in vascular tissue [98]. Elevated $\mathrm{H}_{2} \mathrm{O}_{2}$ levels also initiate IKK activation and NF- $\mathrm{KB}$ signaling [99]. As the M1 proinflammatory phenotype is favored by the activation of the MAPK and NF- $\mathrm{BB}$ signaling pathways, their activation, combined with the presence of ROS, may shift the macrophage phenotype toward M1 and propagate the inflammatory 
cascade [97]. Other specific inflammatory agents also utilize ROS as a member of their signaling cascade [100-102]

\subsection{Regulation of Appetite and Energy Homeostasis}

ROS also play an important role in the central nervous system as a signaling molecule. This is particularly true in the hypothalamus, where they are involved in the regulation of food intake and metabolism processes. They achieve this by exerting an effect on different types of neurons, such as proopiomelanocortin (POMC) neurons and agouti-related protein/neuropeptide $Y$ neurons (NPY/AgRP) $[18,103]$. POMC neurons use glucose as their main fuel and their activation reduces food intake and increases energy expenditure, whereas NPY/AgRP neurons use fatty acids as main fuel and their activation induces increased food intake and decreased energy expenditure [104]. This balance allows the above processes to be regulated. Mitochondrial ROS are present in the hypothalamus. During a positive energy state ROS are produced as a result of glucose, lipid, insulin, and leptin metabolism in POMC and NPY/AgRP neurons via $\mathrm{Ca}^{2+}$ influx and mitochondrial activity. Elevated levels of intracellular ROS stimulates POMC neuron activity and decreases that of NPY/AgRP neurons, thus suppressing food intake and increasing energy expenditure. In a negative energy state, the NPY/AgRP neurons are more active; this decreases the level of ROS by blocking its release. Therefore, oxygen production must be balanced to maintain homeostasis. Overproduction of ROS is related to over-activation of the sympathetic nervous system and may be associated with metabolic disorders, including obesity and related disorders, such as diabetes mellitus type 2 , hypertension and cardiovascular dysfunction $[18,103,105]$.

\section{Obesity—In Vivo and In Vitro Plant Extract Studies}

\subsection{Obesity Cellular Models-In Vitro Studies}

Adipocytes store fuel for the body in the form of neutral triglycerides, with these being converted into fatty acids and released when required. Although adipose tissue is mainly composed of adipocytes, it also contains pre-adipocytes, macrophages, endothelial cells, fibroblasts, and leucocytes. Adipocytes are divided into two general types: White and brown. White adipocytes are most common and possess a high capacity for energy storage. White and brown adipocytes develop from mesenchymal and skeletal muscle-like lineages, respectively [106-108]. Adipose tissue plays a very important role in the regulation of energy homeostasis by secreting adipokines, which take part in lipogenesis and lipolysis. In addition to its role as an energy store, white adipose tissue also plays an important role in mammalian physiology and is regarded as part of the endocrine system.

One of the in vitro screening strategies used in the analysis of the anti-obesity properties of natural plant extracts is based on the inhibition of lipid accumulation in 3T3-L1 pre-adipocyte cells by a quantitative Oil Red O dye method. The enlargement of adipose tissue is preceded by an increase in the number and size of adipocytes formed by adipogenesis from its fibroblastic preadipocyte precursor [109]. This mechanism is extremely important in obesity development. The differentiation process into mature cells involves treatment with several agents after growth arrest, including insulin, synthetic glucocorticoids and phosphodiesterase inhibitor [110]. Oil Red $\mathrm{O}$ is a dye that stains lipids and has been used in the quantitative analysis of adipocyte differentiation and intracellular triglyceride content [111].

All experiments analyzed below were preceded by a cell viability test performed following incubation with an appropriate concentration of plant extracts. In each case, no cytotoxic effects were demonstrated. It was found that several active compounds from various plant species are able to block cell differentiation, suppress adipogenesis, and decrease lipid droplet accumulation and triglyceride level. Selected herb extracts with obtained chemical profile known to have anti-obesity properties, confirmed by experiment on 3T3-L1 cells, are given in Table 1. 
The anti-obesity properties of natural plant extracts can also be determined by porcine pancreatic lipase (PPL) in vitro activity assay. PPL hydrolyzes triacyloglycerol into diglycerides and subsequently into monoglycerides and free fatty acids, which process enable dietary fat to be directly and efficiently absorbed by the intestine [137]. To determine PPL inhibition, the plant extracts are pre-incubated with the enzyme, p-nitrophenyl butyrate is added as substrate and then the amount of p-nitrophenol released is determined spectrophotometrically [138]. The procedure typically uses Orlistat, a derivative of lipstatin, an inhibitor of gastric and pancreatic lipase which is widely used as antiobesity drug [139]. The anti-lipase activity of selected plant extracts is presented in Table 2 with characteristic, chemical profiles.

The data presented in Tables 1 and 2 demonstrate the potential value of the tested plant extract in treating obesity, as confirmed by in vitro studies.

\subsection{Obesity Animal Models—In Vivo Studies}

Animal models, typically Sprague-Dawley (SD) rats, Wistar rats and C57BL/6J mice, are commonly used in the assessment of the weight management potential of plant extracts. The subjects are first given the chance to acclimatize to the specified environmental conditions (appropriate temperatures, humidity, and light and dark cycle). Following this, the animals are typically divided into groups, with one group being fed a normal chow diet and the others being fed different variants of high fat diets containing all essential nutrients, vitamins, minerals and a surplus of fat in order to induce obesity. Measurements are taken at the beginning, over the course of the study and at the end. These measurements commonly consist of body weight, visceral fat and organ weight, and blood biochemistry, including total cholesterol and triglyceride level. Negative and positive control groups with the normal and high fat diet may be administered distilled water and orlistat, respectively. Table 3 presents a number of screened natural plants characterized by chemical profiles which may play a role in alleviating obesity in mouse or rat models. 
Table 1. Selected plant extracts with anti-obesity properties with characteristic chemical profiles, as confirmed in in vitro 3T3-L1 cells.

\begin{tabular}{|c|c|c|c|c|c|c|}
\hline $\mathrm{Nr}$ & Plant Sources & Family Name & Tissue Sampled & Class/Bioactive Compounds & $\begin{array}{c}\text { Concentration of } \\
\text { Extract }\end{array}$ & Ref. \\
\hline 1. & $\begin{array}{l}\text { Ilex paraguariensis } \\
\text { (A.St.-Hil.) }\end{array}$ & Aquifoliaceae & leaf and unripe fruit & Polyphenols & $50-500 \mu \mathrm{g} / \mathrm{mL}$ & [112] \\
\hline 2. & $\begin{array}{l}\text { Panax ginseng (C.A. } \\
\text { Mey.) }\end{array}$ & Araliaceae & root & $\begin{array}{l}\text { Ginsenosides including Rb1, Rb2, Rc, Rd, Re, Rf, Rg1, } \\
\text { Rg2, and Rg3 }\end{array}$ & $10 \mu \mathrm{g} / \mathrm{mL}$ & [113] \\
\hline 3. & $\begin{array}{l}\text { Aster spathulifolius } \\
\quad(\text { Maxim) }\end{array}$ & Asteraceae & leaf & $\begin{array}{c}\text { Chlorogenic acid, isoquercitrin, } \\
\text { luteolin-7-O-rutinoside, 3,4-di-O-caffeoylquinic acid, } \\
\text { 3,5-di-O-caffeoylquinic acid, upatilin. }\end{array}$ & $150-250 \mu \mathrm{g} / \mathrm{mL}$ & [114] \\
\hline 4. & $\begin{array}{c}\text { Taraxacum officinale } \\
\text { (Weber ex F. H. Wigg.) }\end{array}$ & Asteraceae & leaf and root & Caffeic and chlorogenic acids & $300-600 \mu \mathrm{g} / \mathrm{mL}$ & [115] \\
\hline 5. & Pluchea indica (L.) & Asteraceae & whole plant & Polyphenols & $250-1000 \mu \mathrm{g} / \mathrm{mL}$ & [116] \\
\hline 6. & $\begin{array}{l}\text { Oroxylum indicum (L.) } \\
\text { Kurz }\end{array}$ & Bignoniaceae & fruit pods & Flavonoids, alkaloids, steroids, glycoside, and tannins & $50-200 \mu \mathrm{g} / \mathrm{mL}$ & [117] \\
\hline 7. & $\begin{array}{l}\text { Oroxylum indicum (L.) } \\
\text { Kurz }\end{array}$ & Bignoniaceae & bark & Oroxylin A, chrysin and baicalein & $50 \mu \mathrm{g} / \mathrm{mL}$ & [118] \\
\hline 8. & Cornus kousa (L.) & Cornaceae & leaf & $\begin{array}{l}\text { Cyanidin 3-glucoside, delphinidin 3-glucoside and } \\
\text { pelargonidin 3-glucoside }\end{array}$ & $5-100 \mu \mathrm{g} / \mathrm{mL}$ & [119] \\
\hline 9. & Cyprus rotundus (L.) & Cyperaceae & root & Flavonoids, tannins, alkaloid, triterpenoids, saponin & $125 \mu \mathrm{g} / \mathrm{mL}$ & [120] \\
\hline 10. & $\begin{array}{l}\text { Vaccinium corymbosum } \\
\text { (L.) }\end{array}$ & Ericaceae & fruit peel & Polyphenols & $50-300 \mu \mathrm{g} / \mathrm{mL}$ & [121] \\
\hline 11. & Clitoria ternatea (L.) & Fabaceae & flower & $\begin{array}{c}\text { Preternatin A3, ternatin B2, ternatin D2, } \\
\text { quercetin-3-rutinoside, ternatin D1, } \\
\text { kaemferol-3-O-(2-rhamnosyl) rutinoside, } \\
\text { delphinidin-3-glucoside, kaemferol-3-O-rutinoside, } \\
\text { delphinidin-3-O-(6-O-p-coumaryl)glucoside-pyruvic } \\
\text { acid, (+)-catechin 7-O- } \beta \text {-glucoside, } \\
\text { syringetin-3-O-glucoside, quercetin triglycoside, and } \\
\text { delphinidin derivatives }\end{array}$ & $500-1000 \mu \mathrm{g} / \mathrm{mL}$ & [122] \\
\hline 12. & Perilla frutescens (L.) & Lamiaceae & leaf & $\begin{array}{l}\text { Eugenyl glucoside, luteolin-7-O-glucoside, } \\
\text { apigenin-7-O- } \beta \text {-d-glucuronide, } \\
\text { kaempferol-3-O- } \beta \text {-d-glucuronide and rosmarinic acid }\end{array}$ & $100-400 \mu \mathrm{g} / \mathrm{mL}$ & [123] \\
\hline
\end{tabular}


Table 1. Cont.

\begin{tabular}{|c|c|c|c|c|c|c|}
\hline $\mathrm{Nr}$ & Plant Sources & Family Name & Tissue Sampled & Class/Bioactive Compounds & $\begin{array}{c}\text { Concentration of } \\
\text { Extract }\end{array}$ & Ref. \\
\hline 13. & $\begin{array}{c}\text { Cinnamomum cassia } \\
\text { (Presl.) }\end{array}$ & Lauraceae & twig & $\begin{array}{c}\text { Coumarin (1), 2-hydroxyl cinnamaldehyde (2), } \\
\text { cinnamyl alcohol (3), cinnamic acid (4), } \\
\text { cinnamaldehyde (5), 2-methoxy cinnamaldehyde (6), } \\
\text { and eugenol }\end{array}$ & $100-500 \mu \mathrm{g} / \mathrm{mL}$ & [124] \\
\hline 14. & Ficus deltoidei (Jack) & Moraceae & leaf & polyphenols, triterpenoids & $150-300 \mu \mathrm{g} / \mathrm{mL}$ & [125] \\
\hline 15. & Moringa oleifera (Lam.) & Moringaceae & leaf & Isoquercitrin, chrysin-7-glucoside, and quercitrin & $25-400 \mu \mathrm{g} / \mathrm{mL}$ & [126] \\
\hline 16. & $\begin{array}{c}\text { Nelumbo nucifera } \\
\text { (Gaertn.) }\end{array}$ & Nymphaeaceae & petal & Quercetin and kaempferol glycosides & $2-100 \mu \mathrm{g} / \mathrm{mL}$ & [127] \\
\hline 17. & $\begin{array}{c}\text { Nelumbo nucifera } \\
\text { (Gaertn.) }\end{array}$ & Nymphaeaceae & leaf & Megastigmanes, alkaloids, flavonoids & $100 \mu \mathrm{M}$ & [128] \\
\hline 18. & $\begin{array}{c}\text { Passiflora edulis } f . \\
\text { Flavicarpa (Degener) }\end{array}$ & Passifloraceae & leaf & Flavonoids, phenolics, triterpenes, alkaloids & $130.56 \mu \mathrm{g} / \mathrm{mL}$ & [129] \\
\hline 19. & Sasa coreana (Nakai) & Poaceae & leaf & $\begin{array}{l}\text { Caffeic acid, isoorientin, orientin, p-coumaric acid, } \\
\text { vitexin, isovitexin, ferulic acid, hesperidin, naringin, } \\
\text { luteolin }\end{array}$ & $50-100 \mu \mathrm{g} / \mathrm{mL}$ & [130] \\
\hline 20. & Zea mays (L.) & Poaceae & purple corn silk & phenolic acids, flavonoids, anthocyanins & $125-1000 \mu \mathrm{g} / \mathrm{mL}$ & [131] \\
\hline 21. & Coix lachryma-jobi (L.) & Poaceae & seed & Gallic acid, chlorogenic acid, caffeic acid, ferulic acid & $5-30 \mu \mathrm{g} / \mathrm{mL}$ & [132] \\
\hline 22. & $\begin{array}{l}\text { Hovenia dulcis } \\
\text { (Thunb.) }\end{array}$ & Rhamnaceae & fruit & Quercetin & $10-100 \mu \mathrm{g} / \mathrm{mL}$ & [133] \\
\hline 23. & Coffea arabica $(\mathrm{L})$. & Rubiaceae & $\begin{array}{l}\text { fruits: green dry/fresh; } \\
\text { yellow dry/fresh; red } \\
\text { dry/fresh }\end{array}$ & Caffeoylquinic acid, chlorogenic acid, caffeic acid & $200-1000 \mu \mathrm{g} / \mathrm{mL}$ & [134] \\
\hline 24. & $\begin{array}{l}\text { Paullinia cupana } \\
\text { (Kunth) }\end{array}$ & Sapindaceae & seed & Polyphenols & $150 \mu \mathrm{g} / \mathrm{mL}$ & [135] \\
\hline 25. & $\begin{array}{l}\text { Lycium chinense } \\
\text { (Miller) }\end{array}$ & Solanaceae & leaf & $\begin{array}{c}\text { Chlorogenic acid, } \\
\text { kaempferol-3-sophoroside-7-glucoside, } \\
\text { kaempferol-3-sophoroside, kaempferol-3-glucoside, } \\
\text { kaempferol }\end{array}$ & $200 \mu \mathrm{g} / \mathrm{mL}$ & [136] \\
\hline
\end{tabular}


Table 2. Selected plant extract with anti-obesity properties confirmed by porcine pancreatic lipase (PPL) in vitro activity assay with characteristic chemical profiles.

\begin{tabular}{|c|c|c|c|c|c|c|}
\hline $\mathrm{Nr}$ & Plant Sources & Family Name & Tissue Sampled & Class/Bioactive Compounds & $\begin{array}{c}\text { Concentration of } \\
\text { Extract }\end{array}$ & Ref. \\
\hline 1. & $\begin{array}{l}\text { Panax notoginseng } \\
\text { (Burk.) }\end{array}$ & Araliaceae & root & $\begin{array}{c}\text { ginsenoside } \mathrm{Rh} 4,20(\mathrm{~S}) \text {-ginsenoside } \mathrm{Rg} 3 \text { and } \\
\text { 20(R)-ginsenoside } \mathrm{Rg} 3\end{array}$ & $200 \mu \mathrm{g} / \mathrm{mL}$ & [140] \\
\hline 2. & $\begin{array}{l}\text { Cryptolepis elegans } \\
\text { (Wall.) }\end{array}$ & Asclepiadaceae & leaf & Polyphenols & $100 \mu \mathrm{g} / \mathrm{mL}$ & [141] \\
\hline 3. & $\begin{array}{l}\text { Cosmos caudatus } \\
\text { (Kunth.) }\end{array}$ & Asteraceae & leaf & $\begin{array}{c}\text { Quercetin-3-rhamnoside, 1-caffeyolquinic acid, } \\
\text { catechin, kaempherol, kaempherol glucoside, } \\
\text { quercetin, quercetin-3-glucoside, } \\
\text { quercetin-O-pentoside, quercetin-rhamnosyl } \\
\text { galactoside, quinic acid, monogalloyl glucose, and } \\
\text { procyanidin B1 }\end{array}$ & $60-1000 \mu \mathrm{g} / \mathrm{mL}$ & [142] \\
\hline 4. & $\begin{array}{l}\text { Oroxylum indicum (L.) } \\
\text { Kurz }\end{array}$ & Bignoniaceae & fruit pods & $\begin{array}{l}\text { flavonoids, alkaloids, steroids, glycosides, and } \\
\text { tannins }\end{array}$ & $100-1250 \mu \mathrm{g} / \mathrm{mL}$ & [117] \\
\hline 5. & $\begin{array}{l}\text { Oroxylum indicum (L.) } \\
\text { Kurz }\end{array}$ & Bignoniaceae & bark & Oroxylin A, chrysin and baicalein & $250 \mu \mathrm{g} / \mathrm{mL}$ & [118] \\
\hline 6. & $\begin{array}{l}\text { Moricandia arvensis } \\
\text { (L.) }\end{array}$ & Brassicaceae & aerial parts & Kaempferol and quercetin & $1000-2500 \mu \mathrm{g} / \mathrm{mL}$ & [143] \\
\hline 7. & $\begin{array}{c}\text { Stellaria media (Linn.) } \\
\text { Vill }\end{array}$ & Caryophylaceae & whole plant & Polyphenols & $1000-5000 \mu \mathrm{g} / \mathrm{mL}$ & [144] \\
\hline 8. & $\begin{array}{l}\text { Silene vulgaris } \\
\text { (Moench) }\end{array}$ & Caryophyllaceae & leaf & Polyphenols & $100 \mu \mathrm{g} / \mathrm{mL}$ & [145] \\
\hline 9. & $\begin{array}{l}\text { Garcinia mangostana } \\
\text { (Linn.) }\end{array}$ & Clusiaceae & pericarp & Polyphenols, terpenoids & $3.91-125 \mu \mathrm{g} / \mathrm{mL}$ & [146] \\
\hline 10. & $\begin{array}{l}\text { Momordica charantia } \\
\text { (L.) }\end{array}$ & Cucurbitaceae & fruit & $\begin{array}{l}\text { Hydroxybenzoic acids, hydroxycinnamic acid, } \\
\text { flavonol, isoflavonoid, flavanone, hydroxycoumarin }\end{array}$ & $100-400 \mu \mathrm{g} / \mathrm{mL}$ & [147] \\
\hline 11. & $\begin{array}{l}\text { Diospyros kaki } \\
\text { (Thunb.) }\end{array}$ & Ebenaceae & fruit & Polyphenols & $100-200 \mu \mathrm{g} / \mathrm{mL}$ & [148] \\
\hline 12. & Phyllanthus niruri (L.) & Euphorbiaceae & whole plant & Polyphenols & $500 \mu \mathrm{g} / \mathrm{mL}$ & [149] \\
\hline 13. & $\begin{array}{c}\text { Phyllanthus } \\
\text { chamaepeuce (Ridl.) }\end{array}$ & Euphorbiaceae & leaf & Polyphenols & $100 \mu \mathrm{g} / \mathrm{mL}$ & [141] \\
\hline
\end{tabular}


Table 2. Cont.

\begin{tabular}{|c|c|c|c|c|c|c|}
\hline $\mathrm{Nr}$ & Plant Sources & Family Name & Tissue Sampled & Class/Bioactive Compounds & $\begin{array}{c}\text { Concentration of } \\
\text { Extract }\end{array}$ & Ref. \\
\hline 14. & $\begin{array}{c}\text { Garcinia vilersiana } \\
\text { (Pierre) }\end{array}$ & Guttiefrae & leaf & Polyphenols & $100 \mu \mathrm{g} / \mathrm{mL}$ & [141] \\
\hline 15. & $\begin{array}{l}\text { Crocus cancellatus } \\
\text { subsp. Damascenus } \\
\text { (Herb.) }\end{array}$ & Iridaceae & stigma & Catechin hydrate, ferulic and caffeic acids & $5000 \mu \mathrm{g} / \mathrm{mL}$ & [150] \\
\hline 16. & Muscari comosum (L.) & Liliaceae & bulb & Polyphenols & & [151] \\
\hline 17. & $\begin{array}{l}\text { Magnolia officinalis } \\
\text { (Rehd. et Wils) }\end{array}$ & Magnoliaceae & bark & Polyphenols (Honokiol) & $200 \mu \mathrm{g} / \mathrm{mL}$ & [140] \\
\hline 18. & $\begin{array}{l}\text { Memecylon edule } \\
\text { (Roxb.) }\end{array}$ & Melastomataceae & leaf & Polyphenols & $100 \mu \mathrm{g} / \mathrm{mL}$ & [141] \\
\hline 19. & $\begin{array}{l}\text { Nelumbo nucifera } \\
\text { (Gaertn.) }\end{array}$ & Nymphaeaceae & leaf & Megastigmanes, alkaloids, flavonoids & $100 \mu \mathrm{M}$ & [128] \\
\hline 20. & $\begin{array}{l}\text { Passiflora nitida } \\
\text { (Kunth) }\end{array}$ & Passifloraceae & leaf & Orientin, vitexin, swertisina & $100 \mu \mathrm{g} / \mathrm{mL}$ & [152] \\
\hline 21. & Portulaca oleracea (L.) & Portulacaceae & leaf & Polyphenols & $100 \mu \mathrm{g} / \mathrm{mL}$ & [145] \\
\hline 22. & $\begin{array}{l}\text { Rubus grandifolius } \\
\text { (Lowe) }\end{array}$ & Rosaceae & fruit and leaf & Polyphenols & $300-4450 \mu \mathrm{g} / \mathrm{mL}$ & [153] \\
\hline 23. & $\begin{array}{l}\text { Citrus unshiu (S. } \\
\text { Marcov.) }\end{array}$ & Rutaceae & peel & Polyphenols & $100-200 \mu \mathrm{g} / \mathrm{mL}$ & [148] \\
\hline 24. & $\begin{array}{l}\text { Lycium chinense } \\
\text { (Miller) }\end{array}$ & Solanaceae & leaf & $\begin{array}{c}\text { Chlorogenic acid, } \\
\text { kaempferol-3-sophoroside-7-glucoside, } \\
\text { kaempferol-3-sophoroside, kaempferol-3-glucoside, } \\
\text { kaempferol }\end{array}$ & $10-1000 \mu \mathrm{g} / \mathrm{mL}$ & [136] \\
\hline 25. & Capsicum annuum (L.) & Solanaceae & flower & Polyphenols & $100-1000 \mu \mathrm{g} / \mathrm{mL}$ & [154] \\
\hline 26. & $\begin{array}{l}\text { Zygophyllum album } \\
\text { (L.) }\end{array}$ & Zygophyllaceae & Leaf and flower & Polyphenols & $50-200 \mu \mathrm{g} / \mathrm{mL}$ & [155] \\
\hline
\end{tabular}


Table 3. Selected plant extracts with anti-obesity properties confirmed in in vivo mouse or rat models.

\begin{tabular}{|c|c|c|c|c|c|c|c|c|c|}
\hline $\mathrm{Nr}$ & Plant Sources & Family Name & $\begin{array}{c}\text { Tissue } \\
\text { Sampled }\end{array}$ & Class/Bioactive Compounds & $\begin{array}{l}\text { Species of } \\
\text { Animals }\end{array}$ & $\begin{array}{c}\text { Concentration } \\
\text { of Extract }\end{array}$ & $\begin{array}{c}\text { Duration of } \\
\text { Diet }\end{array}$ & Mechanisms of Action & Ref. \\
\hline 1. & $\begin{array}{c}\text { Salicornia } \\
\text { europaea (L.) }\end{array}$ & Amaranthaceae & $\begin{array}{c}\text { desalted } \\
\text { leaves, } \\
\text { branches and } \\
\text { stems }\end{array}$ & $\begin{array}{l}\text { Trans-ferulic acid, caffeic acid, } \\
\text { p-coumaric acid and } \\
\text { isorhamnetin-3- } \beta \text {-d-glucoside }\end{array}$ & $\begin{array}{l}\text { Sprague-Dawley } \\
\text { (SD) rats }\end{array}$ & $\begin{array}{c}250 \text { and } \\
500 \mathrm{mg} / \mathrm{kg}\end{array}$ & 12 weeks & $\begin{array}{l}\text { down-regulation the } \\
\text { adipogenesis-related gene } \\
\text { expression of sterol regulatory } \\
\text { element-binding protein } 1 \\
\text { (SREBP-1), peroxisome } \\
\text { proliferator-activated receptor } \gamma \\
\text { (PPAR } \gamma \text { ), CCAAT/enhancer } \\
\text { binding protein- } \alpha(\mathrm{C} / \mathrm{EBP} \alpha) \text { and } \\
\text { fatty acid (FA) synthase }\end{array}$ & {$[156]$} \\
\hline 2. & $\begin{array}{c}\text { Allium } \\
\text { fistulosum (L.) }\end{array}$ & Amaryllidaceae & $\begin{array}{l}\text { dried bulbs } \\
\text { and roots }\end{array}$ & Ferulic acid and quercetin & $\begin{array}{l}\text { C57BL/6 J } \\
\text { mice }\end{array}$ & $100 \mathrm{mg} / \mathrm{kg}$ & 6 weeks & $\begin{array}{l}\text { attenuation HFD-induced } \\
\text { changes in serum leptin and } \\
\text { insulin-like growth factor } 1 \\
\text { levels, liver expression of AMPK, } \\
\text { and adipose tissue expression of } \\
\text { uncoupling protein } 2 \text { (UCP2) }\end{array}$ & [157] \\
\hline 3. & $\begin{array}{c}\text { Ilex } \\
\text { paraguariensis } \\
\text { (A.St.-Hil.) }\end{array}$ & Aquifoliaceae & $\begin{array}{l}\text { leaf and } \\
\text { unripe fruit }\end{array}$ & Polyphenols & Swiss mice & $1 \mathrm{mg} / \mathrm{kg}$ & 8 weeks & $\begin{array}{l}\text { down-regulation the expression } \\
\text { of genes that regulate } \\
\text { adipogenesis, such as Creb-1and } \\
\text { C/EBP } \alpha \text {, and the extract } \\
\text { up-regulated the expression of } \\
\text { genes related to the inhibition of } \\
\text { adipogenesis, including Dlk1, } \\
\text { Gata2, Gata3, Klf2, Lrp5, Ppar } 2 \text {, } \\
\text { Sfrp1, Tcf712, Wnt10b, and Wnt3a }\end{array}$ & {$[112]$} \\
\hline 4. & $\begin{array}{l}\text { Matricaria } \\
\text { recutita (L.) }\end{array}$ & Asteraceae & flower & $\begin{array}{l}\text { Gallic acid, protocatechuic acid, } \\
\text { chlorogenic acid, cafeic acid, } \\
\text { cafeoylquinic acid, salicylic acid, } \\
\text { quercetin, quinic acid derivative, } \\
\text { hydroxybenzoic acid-o-hexoside, } \\
\text { 5,7,4'-trihydroxy-6,3'-imethoxyflavor }\end{array}$ & $\begin{array}{l}\text { Wistar rats } \\
\text { ne }\end{array}$ & $100 \mathrm{mg} / \mathrm{kg}$ & 6 weeks & $\begin{array}{l}\text { protective effect against obesity } \\
\text { and oxidative stress: inhibiting } \\
\text { effect on intestinal glucose } \\
\text { absorption and/or by negatively } \\
\text { regulating the studied } \\
\text { intracellular mediators such as } \\
\text { calcium, hydrogen peroxide and } \\
\text { free iron }\end{array}$ & {$[158]$} \\
\hline 5. & $\begin{array}{l}\text { Erigeron } \\
\text { breviscapus } \\
\text { (Vant.) }\end{array}$ & Asteraceae & whole plant & $\begin{array}{l}\text { Scutellarin, 3,5-dicaffeoylquinic } \\
\text { acid, 1,5-dicaffeoylquinic acid } \\
\text { and 4,5-dicaffeoylquinic acid }\end{array}$ & C57Bl/6 mice & $2 \%(w / w)$ & 8 weeks & $\begin{array}{l}\text { regulation the expressions of } \\
\text { Cyp7 } \alpha 1, \text { CD36 and PPAR- } \gamma\end{array}$ & [159] \\
\hline
\end{tabular}


Table 3. Cont.

\begin{tabular}{|c|c|c|c|c|c|c|c|c|c|}
\hline $\mathrm{Nr}$ & Plant Sources & Family Name & $\begin{array}{c}\text { Tissue } \\
\text { Sampled }\end{array}$ & Class/Bioactive Compounds & $\begin{array}{l}\text { Species of } \\
\text { Animals }\end{array}$ & $\begin{array}{l}\text { Concentration } \\
\text { of Extract }\end{array}$ & $\begin{array}{c}\text { Duration of } \\
\text { Diet }\end{array}$ & Mechanisms of Action & Ref. \\
\hline 6. & $\begin{array}{l}\text { Artemisia } \\
\text { iwayomogi } \\
\text { (Kitam.) }\end{array}$ & Asteraceae & whole plant & $\begin{array}{l}\text { Scopolin, acetophenone } \\
\text { glycoside, scopoletin }\end{array}$ & C57BL/6J mice & $0.5 \%(w / w)$ & 11 weeks & $\begin{array}{c}\text { downregulation of adipogenic } \\
\text { transcription factors: PPAR } \gamma \text { and } \\
\mathrm{C} / \mathrm{EBP} \alpha \text { and their target genes: } \\
\mathrm{CD} 36 \text {, aP2, and FAS; decreased } \\
\text { gene expression of } \\
\text { proinflammatory cytokines: } \\
\mathrm{TNF} \alpha, \mathrm{MCP} 1 \text {, IL-6, IFN } \alpha \text {, and } \\
\text { INF } \beta \text { in epididymal adipose } \\
\text { tissue }\end{array}$ & [160] \\
\hline 7. & $\begin{array}{l}\text { Aster glehni } \\
\text { (Franchet et } \\
\text { Schmidt) }\end{array}$ & Asteraceae & leaf & Astragalin and kaempferol & C57BL/6J mice & $5 \%(w / w)$ & 10 weeks & $\begin{array}{l}\text { inhibition the expression of } \\
\text { PPAR } \gamma, C / E B P \alpha, \text { SREBP-1, liver } \\
\mathrm{X} \text { receptor, and leptin genes in } \\
\text { the epididymal adipose tissue }\end{array}$ & [161] \\
\hline 8. & $\begin{array}{l}\text { Lithospermum } \\
\text { erythrorhizon } \\
\text { (Siebold \& } \\
\text { Zucc.) }\end{array}$ & Boraginaceae & root & Shikonin derivatives & C57BL/6 mice & $\begin{array}{l}0.25 \%-0.5 \% \\
(w / w)\end{array}$ & 8 weeks & $\begin{array}{l}\text { downregulation of genes } \\
\text { involved in the adipogenesis } \\
\text { pathway }\end{array}$ & [162] \\
\hline 9. & $\begin{array}{l}\text { Stellaria media } \\
\text { (Linn.) Vill }\end{array}$ & Caryophylaceae & whole plant & Polyphenols & $\begin{array}{l}\text { Swiss albino } \\
\text { mice }\end{array}$ & $\begin{array}{l}400 \text { and } 900 \\
\mathrm{mg} / \mathrm{kg}\end{array}$ & 6 weeks & $\begin{array}{l}\text { delay the intestinal absorption of } \\
\text { dietary fat and carbohydrate by } \\
\text { inhibiting digestive enzymes }\end{array}$ & [144] \\
\hline 10. & $\begin{array}{l}\text { Momordica } \\
\text { cymbalaria } \\
\text { (Hook.) }\end{array}$ & Cucurbitaceae & fruit & Gallic acid and rutin & C57BL/6 mice & $25-50 \mathrm{mg} / \mathrm{kg}$ & 10 weeks & $\begin{array}{l}\text { amelioration insulin resistance in } \\
\text { HFD diet fed C57 mice }\end{array}$ & [163] \\
\hline 11. & $\begin{array}{l}\text { Dioscorea } \\
\text { oppositifolia } \\
\text { (L.) }\end{array}$ & Dioscoreaceae & rhizome & Polyphenols & ICR mice & $0.5 \%(w / w)$ & 8 weeks & $\begin{array}{l}\text { suppression of feeding efficiency } \\
\text { and fat absorption }\end{array}$ & [164] \\
\hline
\end{tabular}


Table 3. Cont

\begin{tabular}{|c|c|c|c|c|c|c|c|c|c|}
\hline $\mathrm{Nr}$ & Plant Sources & Family Name & $\begin{array}{c}\text { Tissue } \\
\text { Sampled } \\
\end{array}$ & Class/Bioactive Compounds & $\begin{array}{l}\text { Species of } \\
\text { Animals }\end{array}$ & $\begin{array}{c}\text { Concentration } \\
\text { of Extract }\end{array}$ & $\begin{array}{c}\text { Duration of } \\
\text { Diet }\end{array}$ & Mechanisms of Action & Ref. \\
\hline 12. & $\begin{array}{l}\text { Vaccinium } \\
\text { macrocarpon } \\
\text { (Aiton) }\end{array}$ & Ericaceae & fruit & $\begin{array}{l}\text { Delphinidin 3-sambubioside, } \\
\text { cyanidin 3-lathyroside, rutin, } \\
\text { quercitrin, kaempferol } \\
\text { robinobioside, myricetin } \\
\text { rhamnoside as well as their } \\
\text { aglycones, oligomeric flavan3-ol } \\
\text { type B and A, catechin, } \\
\text { epicatechin and their gallates, } \\
\text { hydroxybenzoic and } \\
\text { hydroxycinnamic acids, } \\
\text { caffeoylquinic acid, a } \\
\text { dihydroxybenzoic acid hexoside } \\
\text { and feruloylquinic acid }\end{array}$ & Wistar rats & $200 \mathrm{mg} / \mathrm{kg}$ & 30 days & $\begin{array}{l}\text { improve the metabolic profile } \\
\text { and reduced oxidative damage } \\
\text { and steatosis }\end{array}$ & [165] \\
\hline 13. & $\begin{array}{l}\text { Vaccinium } \\
\text { corymbosum } \\
\text { (L.) }\end{array}$ & Ericaceae & fruit peel & Polyphenols & SD rats & $60-150 \mathrm{mg} / \mathrm{kg}$ & 5 weeks & $\begin{array}{l}\text { down-regulation of C/EBP } \beta \text {, } \\
\mathrm{C} / \mathrm{EBP} \alpha, \text { and PPAR } \gamma \text { and the } \\
\text { reduction of the phospho-Akt } \\
\text { adipogenic factor in 3T3-L1 cells }\end{array}$ & [121] \\
\hline 14. & $\begin{array}{l}\text { Orthosiphon } \\
\text { stamineus } \\
\text { (Benth.) }\end{array}$ & Lamiaceae & leaf & rosmarinic acid & C57BL/6J mice & $\begin{array}{l}200 \text { and } 400 \\
\mathrm{mg} / \mathrm{kg}\end{array}$ & 8 weeks & impact on lipid metabolism & [166] \\
\hline 15. & $\begin{array}{c}\text { Perilla } \\
\text { frutescens (L.) }\end{array}$ & Lamiaceae & leaf & $\begin{array}{c}\text { Eugenyl glucoside, } \\
\text { luteolin-7-O-glucoside, } \\
\text { apigenin-7-O- } \beta \text {-d-glucuronide, } \\
\text { kaempferol-3-O- } \beta \text {-d-glucuronide } \\
\text { and rosmarinic acid }\end{array}$ & C57BL/6J mice & $\begin{array}{c}100 \text { and } 400 \\
\mathrm{mg} / \mathrm{kg}\end{array}$ & 12 weeks & $\begin{array}{l}\text { downregulation adipogenic gene } \\
\text { and upregulating lipolytic gene } \\
\text { expressions }\end{array}$ & [123] \\
\hline 16. & Cassia tora $(\mathrm{L})$. & Leguminosae & seed & Emodin, aloe-emodin & Wistar rats & $\begin{array}{c}100-300 \\
\mathrm{mg} / \mathrm{kg}\end{array}$ & 8 weeks & $\begin{array}{l}\text { attenuation lipid accumulation } \\
\text { in white adipose tissue via } \\
\text { AMPKsignaling pathway } \\
\text { activation }\end{array}$ & [167] \\
\hline 17. & $\begin{array}{c}\text { Punica } \\
\text { granatum (L.) }\end{array}$ & Lythraceae & leaf & Polyphenols & ICR mice & $\begin{array}{c}400-800 \\
\mathrm{mg} / \mathrm{kg}\end{array}$ & 5 weeks & suppression energy intake & [168] \\
\hline 18. & $\begin{array}{l}\text { Hiptage } \\
\text { madablota } \\
\text { (Gaertn.) }\end{array}$ & Malpighiaceae & root & Terpenoids, polyphenols & Wistar rats & $100-400 \mathrm{mg} /$ & 40 days & $\begin{array}{l}\text { hypophagic and hypolipidemic } \\
\text { effects and provoke the brain } \\
\text { serotonin level }\end{array}$ & [169] \\
\hline
\end{tabular}


Table 3. Cont

\begin{tabular}{|c|c|c|c|c|c|c|c|c|c|}
\hline $\mathrm{Nr}$ & Plant Sources & Family Name & $\begin{array}{c}\text { Tissue } \\
\text { Sampled }\end{array}$ & Class/Bioactive Compounds & $\begin{array}{l}\text { Species of } \\
\text { Animals }\end{array}$ & $\begin{array}{c}\text { Concentration } \\
\text { of Extract }\end{array}$ & $\begin{array}{c}\text { Duration of } \\
\text { Diet }\end{array}$ & Mechanisms of Action & Ref. \\
\hline 19. & Morus alba (L.) & Moraceae & root-bark & Kuwanon G, and Albanin G & C57BL/6J mice & $\begin{array}{c}250 \text { and } \\
500 \mathrm{mg} / \mathrm{kg}\end{array}$ & 7 weeks & appetite control & [170] \\
\hline 20. & Morus alba (L.) & Moraceae & leaf & $\begin{array}{l}\text { Neochlorogenic acid, } \\
\text { cryptochlorogenic, chlorogenic, } \\
\text { rutin, isoquercitrin, astragalin } \\
\text { acid, nicotiflorin, and } \\
\text { protocatechuic acid }\end{array}$ & Wistar rats & $\begin{array}{c}0.5 \%-2 \% \\
(w / w)\end{array}$ & 4 weeks & $\begin{array}{l}\text { regulation adipocytokines, } \\
\text { inflammation and oxidative } \\
\text { stress }\end{array}$ & [171] \\
\hline 21. & Morus alba (L.) & Moraceae & leaf and fruit & $\begin{array}{c}\text { 1-deoxynojirimycin, } \\
\text { cyanidin-3-glucoside, rutin and } \\
\text { resveratrol }\end{array}$ & C57BL/6 mice & $67-167 \mathrm{mg} / \mathrm{kg}$ & 12 weeks & $\begin{array}{l}\text { modulation of obesity-induced } \\
\text { inflammation and oxidative } \\
\text { stress }\end{array}$ & [172] \\
\hline 22. & $\begin{array}{c}\text { Moringa } \\
\text { oleifera (Lam.) }\end{array}$ & Moringaceae & leaf & $\begin{array}{c}\text { Isoquercitrin, } \\
\text { chrysin-7-glucoside, and } \\
\text { quercitrin }\end{array}$ & C57BL/6J mice & $\begin{array}{c}125-500 \\
\mathrm{mg} / \mathrm{kg}\end{array}$ & 14 weeks & $\begin{array}{l}\text { downregulation the expression } \\
\text { of adipogenesis-associated } \\
\text { proteins: (PPAR } \gamma, \mathrm{C} / \mathrm{EBP} \alpha \text { and } \\
\mathrm{C} / \mathrm{EBP} \beta) \text {, and fatty acid synthase } \\
\text { (FAS); increased the degree of } \\
\text { phosphorylation of } \\
\text { AMP-activated protein kinase } \alpha \\
\text { (AMPK } \alpha \text { ) and acetyl-CoA } \\
\text { carboxylase (ACC) }\end{array}$ & [126] \\
\hline 23. & $\begin{array}{l}\text { Nelumbo } \\
\text { nucifera } \\
\text { (Gaertn.) }\end{array}$ & Nelumbonaceae & seed & Polyphenols & SD rats & $400 \mathrm{mg} / \mathrm{kg}$ & 7 weeks & $\begin{array}{l}\text { decrease expression of PPAR } \gamma \\
\text { GLUT4, and leptin in cultured } \\
\text { human adipocytes }\end{array}$ & [173] \\
\hline 24. & $\begin{array}{l}\text { Nelumbo } \\
\text { nucifera } \\
\text { (Gaertn.) }\end{array}$ & Nelumbonaceae & leaf & Polyphenols & Wistar rats & $70-280 \mathrm{mg} / \mathrm{kg}$ & 8 weeks & reduction the lipid components & [174] \\
\hline
\end{tabular}


Table 3. Cont

\begin{tabular}{|c|c|c|c|c|c|c|c|c|c|}
\hline $\mathrm{Nr}$ & Plant Sources & Family Name & $\begin{array}{l}\text { Tissue } \\
\text { Sampled }\end{array}$ & Class/Bioactive Compounds & $\begin{array}{l}\text { Species of } \\
\text { Animals }\end{array}$ & $\begin{array}{l}\text { Concentration } \\
\text { of Extract }\end{array}$ & $\begin{array}{l}\text { Duration of } \\
\text { Diet }\end{array}$ & Mechanisms of Action & Ref. \\
\hline 25. & $\begin{array}{l}\text { Olea europaea } \\
\text { (L.) }\end{array}$ & Oleaceae & leaf & Oleuropein & $\begin{array}{l}\text { C57BL/6N } \\
\text { mice }\end{array}$ & $0.15 \%(w / w)$ & 8 weeks & $\begin{array}{l}\text { reversion the HFD-induced } \\
\text { upregulation of WNT10b- and } \\
\text { galanin-mediated signaling } \\
\text { molecules and key adipogenic } \\
\text { genes (PPAR } \gamma, \text { C/EBP } \alpha \text {, CD36, } \\
\text { FAS, and leptin) moreover } \\
\text { downregulation of thermogenic } \\
\text { genes involved in uncoupled } \\
\text { respiration: SIRT1, peroxisome } \\
\text { proliferator-activated receptor } \\
\text { gamma, coactivator } 1 \text { alpha } \\
\text { (PGC1 } \alpha \text { ), and UCP1; and } \\
\text { mitochondrial biogenesis: } \\
\text { transcription factor A, } \\
\text { mitochondrial, nuclear } \\
\text { respiratory factor-1, and } \\
\text { cyclooxygenase-2) was also } \\
\text { reversed }\end{array}$ & [175] \\
\hline 26. & $\begin{array}{c}\text { Passiflora } \\
\text { nitida (Kunth) }\end{array}$ & Passifloraceae & leaf & Orientin, vitexin, swertisina & SD rats & $100 \mathrm{mg} / \mathrm{kg}$ & 4 weeks & $\begin{array}{l}\text { reduction of lipid absorption and } \\
\text { pancreatic lipase inhibition }\end{array}$ & [162] \\
\hline 27. & $\begin{array}{l}\text { Limonium } \\
\text { tetragonum } \\
\text { (Thunb.) }\end{array}$ & Plumbaginaceae & aerial part & $\begin{array}{l}\text { (-)-epigallocatechin-3-(3"-O-met } \\
\text { gallate, } \\
\text { (-)-epigallocatechin-3-gallate, } \\
\text { and } \\
\text { myricetin-3-O- } \beta \text {-D-galactopyran }\end{array}$ & C57BL/6J mice & $100 \mathrm{mg} / \mathrm{kg}$ & 8 weeks & $\begin{array}{c}\text { suppression of } \\
\text { adipogenesis-related } \\
\text { transcription factors including } \\
\operatorname{PPAR} \gamma, \mathrm{C} / \mathrm{EBP} \alpha, \mathrm{SREBP}-1 \text { and } \\
\text { adipocyte-specific proteins such } \\
\text { as fatty acid synthase (FAS), } \\
\text { lipoprotein lipase (LPL), and } \\
\text { adipocyte fatty acid-binding } \\
\text { protein (aP2) }\end{array}$ & [176] \\
\hline 28. & $\begin{array}{c}\text { Morinda } \\
\text { citrifolia (L.) }\end{array}$ & Rubiaceae & leaf & Rutin & SD rats & $\begin{array}{l}150 \text { and } 350 \\
\mathrm{mg} / \mathrm{kg}\end{array}$ & 12 weeks & $\begin{array}{l}\text { positive influence on the lipid } \\
\text { profiles and a reduction in LDL } \\
\text { levels }\end{array}$ & [177] \\
\hline 29. & $\begin{array}{l}\text { Aegle marmelos } \\
\text { (L.) }\end{array}$ & Rutaceae & leaf & Umbelliferone, esculetin & SD rats & $30 \mathrm{mg} / \mathrm{kg}$ & 2 weeks & $\begin{array}{l}\text { counteract the obesity by } \\
\text { lipolysis in adipocytes }\end{array}$ & {$[178]$} \\
\hline
\end{tabular}


Table 3. Cont

\begin{tabular}{|c|c|c|c|c|c|c|c|c|c|}
\hline $\mathrm{Nr}$ & Plant Sources & Family Name & $\begin{array}{l}\text { Tissue } \\
\text { Sampled }\end{array}$ & Class/Bioactive Compounds & $\begin{array}{l}\text { Species of } \\
\text { Animals }\end{array}$ & $\begin{array}{l}\text { Concentration } \\
\text { of Extract }\end{array}$ & $\begin{array}{c}\text { Duration of } \\
\text { Diet }\end{array}$ & Mechanisms of Action & Ref. \\
\hline 30. & $\begin{array}{c}\text { Nephelium } \\
\text { lappaceum (L.) }\end{array}$ & Sapindaceae & fruit & Geraniin & SD rats & $\begin{array}{c}10 \text { and } 50 \\
\mathrm{mg} / \mathrm{kg}\end{array}$ & 4 weeks & $\begin{array}{l}\text { restore the oxidative stress } \\
\text { observed in the HFD rats }\end{array}$ & [179] \\
\hline 31. & $\begin{array}{l}\text { Camellia } \\
\text { oleifera } \\
\text { (C.Abel) }\end{array}$ & Theaceae & fruit & $\begin{array}{c}\text { Gallic acid, ellagic acid, } \\
\text { 3-O-methylellagic acid } \\
\text { 4'-O- } \beta \text {-D-glucopyranoside }\end{array}$ & ICR mice & $\begin{array}{c}100-300 \\
\mathrm{mg} / \mathrm{kg}\end{array}$ & 30 days & $\begin{array}{l}\text { inhibition fatty acid synthase } \\
\text { activity }\end{array}$ & [180] \\
\hline 32. & $\begin{array}{l}\text { Alpinia } \\
\text { officinarum } \\
\text { (Hance) }\end{array}$ & Zingiberaceae & whole plant & Galangin & C57BL/6J mice & $0.5 \%(w / w)$ & 8 weeks & $\begin{array}{l}\text { suppression protein expressions } \\
\text { of } C / E B P \alpha \text {, fatty acid synthase, } \\
\text { SREBP- } 1 \text {, and PPAR } \gamma \text { in the liver } \\
\text { and adipose tissue }\end{array}$ & {$[181]$} \\
\hline
\end{tabular}

The value of plant extract in treating obesity, as confirmed by in vivo studies, are presented in Table 3 . 


\subsection{Obesity Human Model—In Vivo Studies.}

Numerous plants contain bioactive substances that influence metabolism and fat oxidation. The following section presents selected plant extracts employed in in vivo human study that demonstrate potential in weight management.

An extensively-studied plant due to its anti-obesity properties is Camellia sinensis (L.) Kunzte from the Theaceae family; the species is widely used for making tea, the second most widely-consumed drink after water [182]. Basu et al. [183] examined the impact of green tea on body weight, glucose and lipid profile in 35 patients with obesity metabolic syndrome. The patients were divided into three groups: A control group consuming four cups water/day, a green tea group drinking four cups/day beverage and a supplementation group consuming two capsules/day. The study continued for eight weeks. A significant decrease in body weight and BMI were observed in beverage and supplementation groups as a consequence of elevated oxidation and lipolysis. Elsewhere, significant decreases of weight and BMI were also observed among patients consuming $150 \mathrm{~mL}$ green tea beverage two times a day for eight and 12 weeks compared to controls administered placebo [184]. The study included 99 subjects with a BMI of 24-35 and age between 18-50.

Hibiscus sabdariffa (L.), of the Malvaceae family, is widely grown in many countries and is consumed as a beverage [185]. Clinical trials found 12-week supplementation with H. sabdariffa to be associated with a reduction in body weight, BMI and body fat in thirty-six selected volunteers with BMI $\geqq 27$ (ages 18-65). The controls were treated with placebo consisting of $500 \mathrm{mg}$ starch capsules, while the study group received capsules with $450 \mathrm{mg}$ extract and $50 \mathrm{mg}$ starch [186].

Phaseolus vulgaris (L.) of the Fabaceae family is a legume originating from the American continent. Wild species can be divided into various sub-populations depending on specific geographical regions [187]. Sixty slightly overweight subjects (age 20-45) were divided into two groups: The study group receiving one capsule/day containing $445 \mathrm{mg}$ of $P$. vulgaris beans extract and a control receiving placebo. After a 30-day study period, the supplemented group was found to have lost significantly more weight than the control group [188]. Similar results were obtained in a study of 101 people with BMI of 25-40 and ages between 20 and 50 years: in total, 50 subjects were included into the placebo group and 51 into the study group. Concentration of extract was $1000 \mathrm{mg}$ and the duration of the experiments was sixty days. Again, the supplementation group was found to display significantly greater weight loss [189].

Nigella sativa (L.), of the Ranunculaceae, originates from Asia but is now widely used plant throughout the word. The seeds have been used to treat various diseases and ailments and as flavoring in food. [190]. A three-month clinical study evaluated the efficacy of $N$. sativa supplementation on body weight changes. Men aged 30-45 with central obesity, i.e., a waist circumference $>90 \mathrm{~mm}$, received two capsules of $750 \mathrm{mg}$ extract twice a day, while a negative control group received matching placebo. Both groups consisted of 39 subjects. The results indicate that extract of $N$. sativa can induce significant body weight loss [191].

Gynostemma pentaphyllum (Thunb.) Makino from the Cucurbitaceae family has been widely used in traditional Chinese medicine and as tea, a vegetable and a supplement in Asia, where it is commonly known as Jiao Gu Lan. In a 12-week human clinical trials on 80 subjects with a BMI ranging between 25-30, the study group receiving a $450 \mathrm{mg}$ daily dose of G. pentaphyllum extract demonstrated significantly lower body weight and BMI compared to controls [192].

Kaempferia parviflora (Wall. Ex. Baker) from the Zingiberaceae family is native to Thailand but is widely used in folk medicine in many countries. [193]. Seventy-six healthy subjects (BMI $24-30 \mathrm{~kg} / \mathrm{m}^{2}$, age 20-65 years) were enrolled to the study and assigned into two groups. The study group received $150 \mathrm{mg}$ of extract per day, whereas the control group was administered placebo. After 12 weeks, the study group demonstrated significantly greater reduction of body fat [194].

Carum carvi (L.) from the Apiaceae family is well known medical plant widely used in Asia, Africa and Europe for food as spice [195]. Their property to weight management were evaluate on obese or overweight aerobic-trained female with BMI of $25-39.9 \mathrm{~kg} / \mathrm{m}^{2}$ and ages between 20 and 55 years. Study 
and control group consist of 3 persons per group and volunteers obtained $30 \mathrm{~mL} /$ day of extract or placebo, respectively. Eating habits and an aerobic training duration $180 \mathrm{~min} /$ week were not changed. Participant were examined for 90 days and after then, a significant reduction of body weight has been demonstrated.

Cissus quadrangularis (L.), from the Vitaceae family, is widely used medicinally in Asia and Africa [196]. The activity of C. quadrangularis formula, Cylaris was tested on 123 overweight and obese participants with BMI $>25$ aged between 19-50. Subjects were divided into four groups: Obese with placebo, obese with two daily doses (514 mg each) of Cylaris, obese with formulation and diet (2100-2200 calories/day), and an overweight group with no diet. After eight weeks, the C. quadrangularis formulation appeared to be useful in weight reduction, regardless of diet [197].

Ziziphus jujuba (Mill.) (Jujube), of the Rhamnaceae family, is commonly used in Chinese medicine, and its fruit, named dazao, is widely consumed in Asian countries [198]. The anti-obesity properties of the extract were evaluated on group of 83 participants aged between 20-57 after a three-month period of experiments. The volunteers were divided into three groups, one with normal weight and BMI 18.5-24.9, the second group included overweight subjects with (BMI 25-29.9) and the third group included obese subjects with BMI over 30 . The participants were randomLy administered 5, 15, and $30 \mathrm{~g}$ of Z. jujuba powder. All participants lost weight, but weight loss was greatest in the second and third groups after administration of the highest analyzed dose [199].

These plant extract appear to be good natural alternatives for obesity treatment.

\section{Role of Polyphenols in Mitochondrial Activities, Inflammation and Sympathetic Nervous System Activity and Obesity Management via ROS Neutralization}

Polyphenols are commonly known as the largest phytochemical molecules with antioxidant properties [200]. Mitochondrial dysfunction, hyperplasia and hypertrophy of adipose tissue linked to chronic low-grade inflammation process, over-activation of the sympathetic nervous system are related to ROS overproduction. The presence of high levels of ROS is known to play an important part in the etiology of obesity and overweight, and largely contributes to the related pathological outcomes. Damaged mitochondria must be replaced by new ones. The balance between autophagy and biogenesis is essential and influences several pathological conditions [201]. Some polyphenols have the ability to activate sirtuin 1 in vitro and are potential inducers of mitochondrial biogenesis via deacetylation-mediated PGC-1 $\alpha$ activation [202]. Excess nutrient levels lead to mitochondrial abnormalities and ROS overproduction [203]. Increased adipocyte size and number results in the initiation of the inflammation process; however, polyphenols are able regulate the immunity response by influencing the synthesis of pro-inflammatory factors, such as cytokines, inhibiting TLR and regulating several inflammatory-related pathways, including NF- KB, MAPK, PI3K/AkT, IKK/JNK, and JAK/STAT. They also interfere with immune cell regulation, pro-inflammatory cytokine synthesis, and gene expression. Polyphenols are able to neutralize ROS by donating an electron or hydrogen atom, deactivating its precursor, chelation properties, exerting co-antioxidant activity with essential vitamins, inhibiting the oxidase and arachidonic acid pathways and upregulating SOD, CAT, and GPX enzymes [204,205]. Polyphenols may act as nutraceuticals preventing hypothalamic inflammation and allowing the regulation of energy balance [206].

The in vitro and in vivo studies reviewed above demonstrate that antioxidants, such as polyphenols offer potential in weight reduction and that beneficial dietary strategies may suppress oxidative stress and prevention obesity, related mitochondrial dysfunction, inflammation, and over-activation of the sympathetic nervous system.

\section{Conclusions}

The plant kingdom is a rich source of active components with a range of biological activities; some of which are polyphenols which have demonstrated anti-obesity properties. Obesity is a significant widespread health problem. Currently, most of the world's population live in countries where 
overweight and obesity kills more people than underweight. Even nowadays, despite a range of surgical and pharmacotherapeutic treatments, no efficient risk-free weight management treatment exists. Lifestyle modification, change of diet and increased physical activity are currently regarded as the best option. In addition, in vitro and in vivo data indicate that natural plant supplementation may provide increased health expectancy and significant weight loss through ROS neutralization; the latter can be achieved through their antioxidant capacity, and effects on mitochondrial biogenesis, reduction of inflammation and regulation of the sympathetic nervous system.

Author Contributions: Supervision, A.M.-S.; Conceptualization, H.Z.-B., P.S., K.M., K.Z., M.J., T.S. and R.Z.

Funding: No funding to declare.

Conflicts of Interest: The authors declare no conflict of interest.

\section{References}

1. Sofowora, A.; Ogunbodede, E.; Onayade, A. The role and place of medicinal plants in the strategies for disease prevention. Afr. J. Tradit. Complement. Altern. Med. 2013, 10, 210-229. [CrossRef] [PubMed]

2. WHO Obesity. Available online: https://www.who.int/topics/obesity/en/ (accessed on 15 August 2019).

3. Kelly, T.; Yang, W.; Chen, C.S.; Reynolds, K.; He, J. Global burden of obesity in 2005 and projections to 2030. Int. J. Obes. 2008, 32, 1431-1437. [CrossRef] [PubMed]

4. Hill, J.O.; Catenacci, V.; Wyatt, H.R. Obesity: Overview of an epidemic. Psychiatr. Clin. North. Am. 2005, 28, 1-23. [CrossRef] [PubMed]

5. Hruby, A.; Hu, F.B. The Epidemiology of Obesity: A Big Picture. Pharmacoeconomics 2015, 33, 673-689. [CrossRef] [PubMed]

6. Chooi, Y.C.; Ding, C.; Magkos, F. The epidemiology of obesity. Metabolism 2019, 92, 6-10. [CrossRef] [PubMed]

7. WHO Expert Consultation. Appropriate body-mass index for Asian populations and its implications for policy and intervention strategies. Lancet 2004, 363, 157-163. [CrossRef]

8. Steenbergen, L.; Colzato, L.S. Overweight and cognitive performance: High body mass index is associated with impairment in reactive control during task switching. Front. Nutr. 2017, 4, 51. [CrossRef] [PubMed]

9. Sperrin, M.; Marshall, A.D.; Higgins, V.; Renehan, A.G.; Buchan, I.E. Body mass index relates weight to height differently in women and older adults: Serial cross-sectional surveys in England (1992-2011). J. Public Health 2016, 38, 607-613. [CrossRef] [PubMed]

10. Frank, Q.; Nuttall, M.D. Obesity, BMI, and Health: A Critical Review. Nutr. Today 2015, 50, 117-128.

11. Djalalinia, S.; Qorbani, M.; Peykari, N.; Kelishadi, R. Health Impacts of Obesity-Obesity Canada. Pak. J. Med. Sci. 2015, 31, 239-242.

12. Hruby, A.; Manson, J.A.E.; Qi, L.; Malik, V.S.; Rimm, E.B.; Sun, Q.; Willett, W.C.; Hu, F.B. Determinants and consequences of obesity. Am. J. Public Health 2016, 106, 1656-1662. [CrossRef]

13. Pi-Sunyer, X. The medical risks of obesity. Postgrad. Med. 2009, 121, 21-33. [CrossRef]

14. Di Meo, S.; Reed, T.T.; Venditti, P.; Victor, V.M. Role of ROS and RNS Sources in Physiological and Pathological Conditions. Oxid. Med. Cell. Longev. 2016, 2016, 1245049. [CrossRef]

15. Cho, K.J.; Seo, J.M.; Kim, J.H. Bioactive lipoxygenase metabolites stimulation of NADPH oxidases and reactive oxygen species. Mol. Cells 2011, 32,1-5. [CrossRef]

16. Waśkiewicz, A.; Beszterda, M.; Goliński, P. Nonenzymatic Antioxidants in Plants. In Oxidative Damage to Plants, 1st ed.; Ahmad, P., Ed.; Academic Press: Cambridge, MA, USA, 2014; pp. 201-234.

17. Yoboue, E.D.; Mougeolle, A.; Kaiser, L.; Averet, N.; Rigoulet, M.; Devin, A. The role of mitochondrial biogenesis and ROS in the control of energy supply in proliferating cells. Biochim. Biophys. Acta 2014, 1837, 1093-1098. [CrossRef]

18. Timper, K.; Brüning, J.C. Hypothalamic circuits regulating appetite and energy homeostasis: Pathways to obesity. Dis. Model. Mech. 2017, 10, 679-689. [CrossRef]

19. Pizzino, G.; Irrera, N.; Cucinotta, M.; Pallio, G.; Mannino, F.; Arcoraci, V.; Squadrito, F.; Altavilla, D.; Bitto, A. Oxidative Stress: Harms and Benefits for Human Health. Oxid. Med. Cell. Longev. 2017, 2017, 8416763. [CrossRef] 
20. Biesalski, H.K.; Dragsted, L.O.; Elmadfa, I.; Grossklaus, R.; Müller, M.; Schrenk, D.; Walter, P.; Weber, P. Bioactive compounds: Definition and assessment of activity. Nutrition 2009, 25, 1202-1205. [CrossRef]

21. Puri, B.; Hall, A. Phytochemical Dictionary. A Handbook of Bioactive Compounds from Plants, 2nd ed.; Taylor \& Francis Group: Abingdon, UK, 1998.

22. Tsao, R. Chemistry and biochemistry of dietary polyphenols. Nutrients 2010, 2, 1231-1246. [CrossRef]

23. Kulbat, K. Biotechnology and Food Sciences The role of phenolic compounds in plant resistance. Biotechnol. Food Sci. 2016, 80, 97-108.

24. Wink, M. Plant secondary metabolites modulate insect behavior-steps toward addiction? Front. Physiol. 2018, 9, 364. [CrossRef]

25. Neill, S.O. The functional role of anthocyanins in leaves. Ph.D. Thesis, University of Auckland, Auckland, New Zealand, 2002.

26. Daglia, M. Polyphenols as antimicrobial agents. Curr. Opin. Biotechnol. 2012, 23, 174-181. [CrossRef]

27. Han, X.; Shen, T.; Lou, H. Dietary polyphenols and their biological significance. Int. J. Mol. Sci. 2007, 8, 950-988. [CrossRef]

28. Tungmunnithum, D.; Thongboonyou, A.; Pholboon, A.; Yangsabai, A. Flavonoids and Other Phenolic Compounds from Medicinal Plants for Pharmaceutical and Medical Aspects: An Overview. Medicines 2018, 5, 93. [CrossRef]

29. Liou, G.-Y.; Storz, P. Reactive oxygen species in cancer. Free Radic. Res. 2010, 44, 479-496. [CrossRef]

30. Asmat, U.; Abad, K.; Ismail, K. Diabetes mellitus and oxidative stress-A concise review. Saudi Pharm. J. 2016, 24, 547-553. [CrossRef]

31. Volpe, C.M.O.; Villar-Delfino, P.H.; Dos Anjos, P.M.F.; Nogueira-Machado, J.A. Cellular death, reactive oxygen species (ROS) and diabetic complications review-Article. Cell Death Dis. 2018, 9, 119. [CrossRef]

32. Mittal, M.; Siddiqui, M.R.; Tran, K.; Reddy, S.P.; Malik, A.B. Reactive Oxygen Species in Inflammation and Tissue Injury. Antioxid. Redox Signal. 2014, 20, 1126-1167. [CrossRef]

33. Panth, N.; Paudel, K.R.; Parajuli, K. Reactive Oxygen Species: A Key Hallmark of Cardiovascular Disease. Adv. Med. 2016, 2016, 9152732. [CrossRef]

34. Liu, Z.; Zhou, T.; Ziegler, A.C.; Dimitrion, P.; Zuo, L. Oxidative Stress in Neurodegenerative Diseases: From Molecular Mechanisms to Clinical Applications. Oxid. Med. Cell. Longev. 2017, 2017, 2525967. [CrossRef]

35. Perron, N.R.; Brumaghim, J.L. A review of the antioxidant mechanisms of polyphenol compounds related to iron binding. Cell Biochem. Biophys. 2009, 53, 75-100. [CrossRef]

36. Skibsted, L.H. Vitamin and non-vitamin antioxidants and their interaction in food. J. Food Drug Anal. 2012, 20, 355-358.

37. Dai, F.; Chen, W.F.; Zhou, B. Antioxidant synergism of green tea polyphenols with $\alpha$-tocopherol and l-ascorbic acid in SDS micelles. Biochimie 2008, 90, 1499-1505. [CrossRef]

38. Hong, J.; Smith, T.J.; Ho, C.T.; August, D.A.; Yang, C.S. Effects of purified green and black tea polyphenols on cyclooxygenase- and lipoxygenase-dependent metabolism of arachidonic acid in human colon mucosa and colon tumor tissues. Biochem. Pharmacol. 2001, 62, 1175-1183. [CrossRef]

39. Ribeiro, V.M.; Bede, T.P.; Rocha, G.; Barroso, S.; Valença, S.; De Azeredo, V.B. High fat diet and high polyphenols beverages effects in enzymatic and non-enzymatic antioxidant activity. Nutr. Hosp. 2017, 35, 169-175. [CrossRef]

40. Sroka, Z.; Cisowski, W. Hydrogen peroxide scavenging, antioxidant and anti-radical activity of some phenolic acids. Food Chem. Toxicol. 2003, 41,753-758. [CrossRef]

41. Bhatti, J.S.; Bhatti, G.K.; Reddy, P.H. Mitochondrial dysfunction and oxidative stress in metabolic disorders-A step towards mitochondria based therapeutic strategies. Biochim. Biophys. Acta Mol. Basis Dis. 2017, 1863, 1066-1077. [CrossRef]

42. Serra, D.; Mera, P.; Malandrino, M.I.; Mir, J.F.; Herrero, L. Mitochondrial fatty acid oxidation in obesity. Antioxid. Redox Signal. 2013, 19, 269-284. [CrossRef]

43. Bournat, J.C.; Brown, C.W. Mitochondrial Dysfunction in Obesity. Curr. Opin. Endocrinol. Diabetes Obes. 2010, 17, 446-452. [CrossRef]

44. Pintus, F.; Floris, G.; Rufini, A. Nutrient availability links mitochondria, apoptosis, and obesity. Aging 2012, 4, 734-741. [CrossRef]

45. Lee, S.J.; Zhang, J.; Choi, A.M.K.; Kim, H.P. Mitochondrial dysfunction induces formation of lipid droplets as a generalized response to stress. Oxid. Med. Cell. Longev. 2013, 2013, 327167. [CrossRef] 
46. Palikaras, K.; Lionaki, E.; Tavernarakis, N. Mechanisms of mitophagy in cellular homeostasis, physiology and pathology. Nat. Cell Biol. 2018, 20, 1013-1022. [CrossRef]

47. Bouchez, C.; Devin, A. Mitochondrial Biogenesis and Mitochondrial Reactive Oxygen Species (ROS): A Complex Relationship Regulated by the cAMP/PKA Signaling Pathway. Cells 2019, 8, 287. [CrossRef]

48. Hernández-Aguilera, A.; Rull, A.; Rodríguez-Gallego, E.; Riera-Borrull, M.; Luciano-Mateo, F.; Camps, J.; Menéndez, J.A.; Joven, J. Mitochondrial dysfunction: A basic mechanism in inflammation-related non-communicable diseases and therapeutic opportunities. Mediators Inflamm. 2013, 2013, 135698. [CrossRef]

49. Cunarro, J.; Casado, S.; Lugilde, J.; Tovar, S. Hypothalamic mitochondrial dysfunction as a target in obesity and metabolic disease. Front. Endocrinol. 2018, 9, 283. [CrossRef]

50. Coelho, M.; Oliveira, T.; Fernandes, R. Biochemistry of adipose tissue: An endocrine organ. Arch. Med. Sci. 2013, 9, 191-200. [CrossRef]

51. Makki, K.; Froguel, P.; Wolowczuk, I. Adipose Tissue in Obesity-Related Inflammation and Insulin Resistance: Cells, Cytokines, and Chemokines. ISRN Inflamm. 2013, 2013, 139239. [CrossRef]

52. Castro, A.M.; Macedo-de la Concha, L.E.; Pantoja-Meléndez, C.A. Low-grade inflammation and its relation to obesity and chronic degenerative diseases. Rev. Médica del Hosp. Gen. México 2016, 80, 101-105. [CrossRef]

53. Liu, G.S.; Chan, E.C.; Higuchi, M.; Dusting, G.J.; Jiang, F. Redox Mechanisms in Regulation of Adipocyte Differentiation: Beyond a General Stress Response. Cells 2012, 1, 976-993. [CrossRef]

54. Castro, J.P.; Grune, T.; Speckmann, B. The two faces of reactive oxygen species (ROS) in adipocyte function and dysfunction. Biol. Chem. 2016, 397, 709-724. [CrossRef]

55. Hakuno, F.; Takahashi, S.I. IGF1 receptor signaling pathways. J. Mol. Endocrinol. 2018, 61, T69-T86. [CrossRef]

56. Son, Y.; Kim, S.; Chung, H.T.; Pae, H.O. Reactive oxygen species in the activation of MAP kinases. Methods Enzymol. 2013, 528, 27-48.

57. Grimaldi, P.A. The roles of PPARs in adipocyte differentiation. Prog. Lipid Res. 2001, 40, 269-281. [CrossRef]

58. Schopfer, F.J.; Cole, M.P.; Groeger, A.L.; Chen, C.S.; Khoo, N.K.; Woodcock, S.R.; Golin-Bisello, F.; Motanya, U.N.; Li, Y.; Zhang, J.; et al. Covalent peroxisome proliferator-activated receptor gamma adduction by nitro-fatty acids: Selective ligand activity and anti-diabetic signaling actions. J. Biol. Chem. 2010, 285, 12321-12333. [CrossRef]

59. Kim, J.W.; Tang, Q.Q.; Li, X.; Lane, M.D. Effect of phosphorylation and S-S bond-induced dimerization on DNA binding and transcriptional activation by C/EBPbeta. Proc. Natl. Acad. Sci. USA 2007, 104, 1800-1804. [CrossRef]

60. Jankovic, A.; Korac, A.; Buzadzic, B.; Otasevic, V.; Stancic, A.; Daiber, A.; Korac, B. Redox implications in adipose tissue (dys)function-A new look at old acquaintances. Redox Biol. 2015, 6, 19-32. [CrossRef]

61. Chen, L.; Deng, H.; Cui, H.; Fang, J.; Zuo, Z.; Deng, J.; Li, Y.; Wang, X.; Zhao, L. Inflammatory responses and inflammation-associated diseases in organs. Oncotarget 2017, 9, 7204-7218. [CrossRef]

62. Ellulu, M.S.; Patimah, I.; Khaza'ai, H.; Rahmat, A.; Abed, Y. Obesity \& inflammation: The linking mechanism \& the complications. Arch. Med. Sci. 2017, 13, 851-863.

63. El-Kenawi, A.; Ruffell, B. Inflammation, ROS, and Mutagenesis. Cancer Cell 2017, 32, 727-729. [CrossRef]

64. Castaner, O.; Goday, A.; Park, Y.M.; Lee, S.H.; Magkos, F.; Shiow, S.A.T.E.; Schröder, H. The gut microbiome profile in obesity: A systematic review. Int. J. Endocrinol. 2018, 2018, 4095789. [CrossRef]

65. Tanti, J.F.; Ceppo, F.; Jager, J.; Berthou, F. Implication of inflammatory signaling pathways in obesity-induced insulin resistance. Front. Endocrinol. 2013, 3, 181. [CrossRef]

66. Erridge, C.; Samani, N.J. Saturated fatty acids do not directly stimulate toll-like receptor signaling. Arterioscler. Thromb. Vasc. Biol. 2009, 29, 1944-1949. [CrossRef]

67. Pal, D.; Dasgupta, S.; Kundu, R.; Maitra, S.; Das, G.; Mukhopadhyay, S.; Ray, S.; Majumdar, S.S.; Bhattacharya, S. Fetuin-A acts as an endogenous ligand of TLR4 to promote lipid-induced insulin resistance. Nat. Med. 2012, 18, 1279-1285. [CrossRef]

68. Li, L.; Chen, L.; Hu, L.; Liu, Y.; Sun, H.Y.; Tang, J.; Hou, Y.J.; Chang, Y.X.; Tu, Q.Q.; Feng, G.S.; et al. Nuclear Factor High-mobility Group Box1 Mediating the Activation of Toll-like Receptor 4 Signaling in Hepatocytes in the Early Stage of Non-alcoholic Fatty Liver Disease in Mice. Hepatology 2011, 54, 1620-1630. [CrossRef]

69. Fischer, H.; Ellström, P.; Ekström, K.; Gustafsson, L.; Gustafsson, M.; Svanborg, C. Ceramide as a TLR4 agonist; a putative signalling intermediate between sphingolipid receptors for microbial ligands and TLR4. Cell. Microbiol. 2007, 9, 1239-1251. [CrossRef] 
70. Oliveira-Marques, V.; Marinho, H.S.; Cyrne, L.; Antunes, F. Role of Hydrogen Peroxide in NF-кB Activation: From Inducer to Modulator. Antioxid. Redox Signal. 2009, 11, 2223-2243. [CrossRef]

71. Morgan, M.J.; Liu, Z.G. Crosstalk of reactive oxygen species and NF-kB signaling. Cell Res. 2011, 21, $103-115$. [CrossRef]

72. Akhter, N.; Madhoun, A.; Arefanian, H.; Wilson, A.; Kochumon, S.; Thomas, R.; Shenouda, S.; Al-Mulla, F.; Ahmad, R.; Sindhu, S. Oxidative Stress Induces Expression of the Toll-Like Receptors (TLRs) 2 and 4 in the Human Peripheral Blood Mononuclear Cells: Implications for Metabolic Inflammation. Cell. Physiol. Biochem. 2019, 53, 1-18.

73. Nisr, R.B.; Shah, D.S.; Ganley, I.G.; Hundal, H.S. Proinflammatory NFkB signalling promotes mitochondrial dysfunction in skeletal muscle in response to cellular fuel overloading. Cell. Mol. Life Sci. 2019, 2019, 1-18. [CrossRef]

74. Vandanmagsar, B.; Youm, Y.H.; Ravussin, A.; Galgani, J.E.; Stadler, K.; Mynatt, R.L.; Ravussin, E.; Stephens, J.M.; Dixit, V.D. The NLRP3 inflammasome instigates obesity-induced inflammation and insulin resistance. Nat. Med. 2011, 17, 179-188. [CrossRef]

75. Koenen, T.B.; Stienstra, R.; Van Tits, L.J.; Joosten, L.A.B.; Van Velzen, J.F.; Hijmans, A.; Pol, J.A.; Van Der Vliet, J.A.; Netea, M.G.; Tack, C.J.; et al. The inflammasome and caspase-1 activation: A new mechanism underlying increased inflammatory activity in human visceral adipose tissue. Endocrinology 2011, 152, 3769-3778. [CrossRef]

76. Yang, Y.; Wang, H.; Kouadir, M.; Song, H.; Shi, F. Recent advances in the mechanisms of NLRP3 inflammasome activation and its inhibitors. Cell Death Dis. 2019, 10, 128. [CrossRef]

77. Gianfrancesco, M.A.; Dehairs, J.; L’homme, L.; Herinckx, G.; Esser, N.; Jansen, O.; Habraken, Y.; Lassence, C.; Swinnen, J.V.; Rider, M.H.; et al. Saturated fatty acids induce NLRP3 activation in human macrophages through $\mathrm{K}+$ efflux resulting from phospholipid saturation and $\mathrm{Na}, \mathrm{K}-\mathrm{ATPase}$ disruption. Biochim. Biophys. Acta Mol. Cell Biol. Lipids 2019, 1864, 1017-1030. [CrossRef]

78. Abais, J.M.; Xia, M.; Zhang, Y.; Boini, K.M.; Li, P.-L. Redox Regulation of NLRP3 Inflammasomes: ROS as Trigger or Effector? Antioxid. Redox Signal. 2015, 22, 1111-1129. [CrossRef]

79. Wen, H.; Gris, D.; Lei, Y.; Jha, S.; Zhang, L.; Huang, M.T.H.; Brickey, W.J.; Ting, J.P.Y. Fatty acid-induced NLRP3-ASC inflammasome activation interferes with insulin signaling. Nat. Immunol. 2011, 12, 408-415. [CrossRef]

80. He, Y.; Zeng, M.Y.; Yang, D.; Motro, B.; Núñez, G. NEK7 is an essential mediator of NLRP3 activation downstream of potassium efflux. Nature 2016, 530, 354-357. [CrossRef]

81. Pagliassotti, M.J.; Kim, P.Y.; Estrada, A.L.; Stewart, C.M.; Gentile, C.L. Endoplasmic reticulum stress in obesity and obesity-related disorders: An expanded view. Metabolism 2016, 65, 1238-1246. [CrossRef]

82. Tam, A.B.; Mercado, E.L.; Hoffmann, A.; Niwa, M. ER Stress Activates NF- $\kappa$ B by Integrating Functions of Basal IKK Activity, IRE1 and PERK. PLoS ONE 2012, 7, e45078. [CrossRef]

83. Liu, T.; Zhang, L.; Joo, D.; Sun, S.C. NF-kB signaling in inflammation. Signal. Transduct. Target. Ther. 2017, 2, 17023. [CrossRef]

84. Boaru, S.G.; Borkham-Kamphorst, E.; Van De Leur, E.; Lehnen, E.; Liedtke, C.; Weiskirchen, R. NLRP3 inflammasome expression is driven by NF-кB in cultured hepatocytes. Biochem. Biophys. Res. Commun. 2015, 458, 700-706. [CrossRef]

85. Ali Khan, H.; Mutus, B. Protein disulfide isomerase a multifunctional protein with multiple physiological roles. Front. Chem. 2014, 2, 70. [CrossRef]

86. Parakh, S.; Atkin, J.D. Novel roles for protein disulphide isomerase in disease states: A double edged sword? Front. Cell Dev. Biol. 2015, 3, 30. [CrossRef]

87. Zeeshan, H.M.A.; Lee, G.H.; Kim, H.R.; Chae, H.J. Endoplasmic reticulum stress and associated ROS. Int. J. Mol. Sci. 2016, 17, 327. [CrossRef]

88. Kawasaki, N.; Asada, R.; Saito, A.; Kanemoto, S.; Imaizumi, K. Obesity-induced endoplasmic reticulum stress causes chronic inflammation in adipose tissue. Sci. Rep. 2012, 2, 799. [CrossRef]

89. Sun, K.; Kusminski, C.M.; Scherer, P.E. Adipose tissue remodeling and obesity. J. Clin. Investig. 2011, 121, 2094-2101. [CrossRef]

90. Engin, A.B. Adipocyte-macrophage cross-talk in obesity. Adv. Exp. Med. Biol. 2017, 960, 327-343.

91. Locati, M.; Mantovani, A.; Sica, A. Macrophage Activation and Polarization as an Adaptive Component of Innate Immunity. Adv. Immunol. 2013, 120, 163-184. 
92. Shapouri-Moghaddam, A.; Mohammadian, S.; Vazini, H.; Taghadosi, M.; Esmaeili, S.A.; Mardani, F.; Seifi, B.; Mohammadi, A.; Afshari, J.T.; Sahebkar, A. Macrophage plasticity, polarization, and function in health and disease. J. Cell. Physiol. 2018, 233, 6425-6440. [CrossRef]

93. Lumeng, C.N.; Bodzin, J.L.; Saltiel, A.R. Obesity induces a phenotypic switch in adipose tissue macrophage polarization. J. Clin. Investig. 2007, 117, 175-184. [CrossRef]

94. Goossens, G.H.; Blaak, E.E. Adipose tissue dysfunction and impaired metabolic health in human obesity: A matter of oxygen? Front. Endocrinol. 2015, 6, 55. [CrossRef]

95. Fujisaka, S.; Usui, I.; Ikutani, M.; Aminuddin, A.; Takikawa, A.; Tsuneyama, K.; Mahmood, A.; Goda, N.; Nagai, Y.; Takatsu, K.; et al. Adipose tissue hypoxia induces inflammatory M1 polarity of macrophages in an HIF-1 $\alpha$-dependent and HIF-1 $\alpha$-independent manner in obese mice. Diabetologia 2013, 56, 1403-1412. [CrossRef]

96. Sabio, G.; Davis, R.J. TNF and MAP kinase signalling pathways. Semin. Immunol. 2014, 26, $237-245$. [CrossRef]

97. Tan, H.Y.; Wang, N.; Li, S.; Hong, M.; Wang, X.; Feng, Y. The Reactive Oxygen Species in Macrophage Polarization: Reflecting Its Dual Role in Progression and Treatment of Human Diseases. Oxid. Med. Cell. Longev. 2016, 2016, 2795090. [CrossRef]

98. Yang, J.; Park, Y.; Zhang, H.; Xu, X.; Laine, G.A.; Dellsperger, K.C.; Zhang, C. Feed-forward signaling of TNF- $\alpha$ and NF- $\mathrm{KB}$ via IKK- $\beta$ pathway contributes to insulin resistance and coronary arteriolar dysfunction in type 2 diabetic mice. Am. J. Physiol. Circ. Physiol. 2009, 296, H1850-H1858. [CrossRef]

99. Takada, Y.; Mukhopadhyay, A.; Kundu, G.C.; Mahabeleshwar, G.H.; Singh, S.; Aggarwal, B.B. Hydrogen peroxide activates NF- $\kappa B$ through tyrosine phosphorylation of $\mathrm{I} \kappa \mathrm{B} \alpha$ and serine phosphorylation of $\mathrm{p} 65$. Evidence for the involvement of IKB $\alpha$ kinase and Syk protein-tyrosine kinase. J. Biol. Chem. 2003, 278, 24233-24241. [CrossRef]

100. Li, Q.; Harraz, M.M.; Zhou, W.; Zhang, L.N.; Ding, W.; Zhang, Y.; Eggleston, T.; Yeaman, C.; Banfi, B.; Engelhardt, J.F. Nox2 and Rac1 Regulate H2O2-Dependent Recruitment of TRAF6 to Endosomal Interleukin-1 Receptor Complexes. Mol. Cell. Biol. 2006, 26, 140-154. [CrossRef]

101. Park, H.S.; Jung, H.Y.; Park, E.Y.; Kim, J.; Lee, W.J.; Bae, Y.S. Cutting Edge: Direct Interaction of TLR4 with $\mathrm{NAD}(\mathrm{P}) \mathrm{H}$ Oxidase 4 Isozyme Is Essential for Lipopolysaccharide-Induced Production of Reactive Oxygen Species and Activation of NF-kB. J. Immunol. 2004, 173, 3589-3593. [CrossRef]

102. Gloire, G.; Legrand-Poels, S.; Piette, J. NF- $\kappa$ B activation by reactive oxygen species: Fifteen years later. Biochem. Pharmacol. 2006, 72, 1493-1505. [CrossRef]

103. Drougard, A.; Fournel, A.; Valet, P.; Knauf, C. Impact of hypothalamic reactive oxygen species in the regulation of energy metabolism and food intake. Front. Neurosci. 2015, 9, 56. [CrossRef]

104. Toda, C.; Santoro, A.; Kim, J.D.; Diano, S. POMC Neurons: From Birth to Death. Annu. Rev. Physiol. 2017, 79, 209-236. [CrossRef]

105. Gyengesi, E.; Paxinos, G.; B Andrews, Z. Oxidative Stress in the Hypothalamus: The Importance of Calcium Signaling and Mitochondrial ROS in Body Weight Regulation. Curr. Neuropharmacol. 2012, 10, $344-353$. [CrossRef]

106. Trayhurn, P.; Beattie, J.H. Physiological role of adipose tissue: White adipose tissue as an endocrine and secretory organ. Proc. Nutr. Soc. 2001, 60, 329-339. [CrossRef]

107. Luo, L.; Liu, M. Adipose tissue in control of metabolism. J. Endocrinol. 2016, 231, R77-R99. [CrossRef]

108. Sethi, J.K.; Vidal-Puig, A.J. Thematic review series: Adipocyte biology. Adipose tissue function and plasticity orchestrate nutritional adaptation. J. Lipid Res. 2007, 48, 1253-1262. [CrossRef]

109. Ghaben, A.L.; Scherer, P.E. Adipogenesis and metabolic health. Nat. Rev. Mol. Cell Biol. 2019. [CrossRef]

110. Morrison, S.; McGee, S.L. 3T3-L1 adipocytes display phenotypic characteristics of multiple adipocyte lineages. Adipocyte 2015, 4, 295-302. [CrossRef]

111. Kraus, N.A.; Ehebauer, F.; Zapp, B.; Rudolphi, B.; Kraus, B.J.; Kraus, D. Quantitative assessment of adipocyte differentiation in cell culture. Adipocyte 2016, 5, 351-358. [CrossRef]

112. Arçari, D.P.; Santos, J.C.; Gambero, A.; Ribeiro, M.L. The in vitro and in vivo effects of yerba mate (Ilex paraguariensis) extract on adipogenesis. Food Chem. 2013, 141, 809-815. [CrossRef]

113. Shin, S.S.; Yoon, M. Korean red ginseng (Panax ginseng) inhibits obesity and improves lipid metabolism in high fat diet-fed castrated mice. J. Ethnopharmacol. 2018, 210, 80-87. [CrossRef] 
114. Kim, S.J.; Choung, S.Y. Inhibitory effects of Aster spathulifolius extract on adipogenesis and lipid accumulation in 3T3-L1 preadipocytes. J. Pharm. Pharmacol. 2016, 68, 107-118. [CrossRef]

115. González-Castejón, M.; García-Carrasco, B.; Fernández-Dacosta, R.; Dávalos, A.; Rodriguez-Casado, A. Reduction of adipogenesis and lipid accumulation by taraxacum officinale (dandelion) extracts in 3T3L1 adipocytes: An in vitro study. Phyther. Res. 2014, 28, 745-752. [CrossRef]

116. Sirichaiwetchakoon, K.; Lowe, G.M.; Thumanu, K.; Eumkeb, G. The Effect of Pluchea indica (L.) Less. Tea on Adipogenesis in 3T3-L1 Adipocytes and Lipase Activity. Evidence-Based Complement. Altern. Med. 2018, 2018, 4108787. [CrossRef]

117. Hengpratom, T.; Lowe, G.M.; Thumanu, K.; Suknasang, S.; Tiamyom, K.; Eumkeb, G. Oroxylum indicum (L.) Kurz extract inhibits adipogenesis and lipase activity in vitro. BMC Complement. Altern. Med. 2018, 18, 177. [CrossRef]

118. Mangal, P.; Khare, P.; Jagtap, S.; Bishnoi, M.; Kondepudi, K.K.; Bhutani, K.K. Screening of six Ayurvedic medicinal plants for anti-obesity potential: An investigation on bioactive constituents from Oroxylum indicum (L.) Kurz bark. J. Ethnopharmacol. 2017, 197, 138-146. [CrossRef]

119. Khan, M.I.; Shin, J.H.; Shin, T.S.; Kim, M.Y.; Cho, N.J.; Kim, J.D. Anthocyanins from Cornus kousa ethanolic extract attenuate obesity in association with anti-angiogenic activities in 3T3-L1 cells by down-regulating adipogeneses and lipogenesis. PLoS ONE 2018, 13, e0208556. [CrossRef]

120. Fathima, A.; Khanum, F.; Ilaiyaraja, N. In-vitro anti-obesity efficacy of selected plants in 3T3-11 cell line. Int. J. Pharm. Sci. Res. 2018, 9, 4666-4673.

121. Song, Y.; Park, H.J.; Kang, S.N.; Jang, S.H.; Lee, S.J.; Ko, Y.G.; Kim, G.S.; Cho, J.H. Blueberry Peel Extracts Inhibit Adipogenesis in 3T3-L1 Cells and Reduce High-Fat Diet-Induced Obesity. PLoS ONE 2013, 8, e69925. [CrossRef]

122. Chayaratanasin, P.; Caobi, A.; Suparpprom, C.; Saenset, S.; Pasukamonset, P.; Suanpairintr, N.; Barbieri, M.A.; Adisakwattana, S. Clitoria ternatea Flower Petal Extract Inhibits Adipogenesis and Lipid Accumulation in 3T3-L1 Preadipocytes by Downregulating Adipogenic Gene Expression. Molecules 2019, 24, 1894. [CrossRef]

123. Thomas, S.S.; Kim, M.; Lee, S.J.; Cha, Y.S. Antiobesity Effects of Purple Perilla (Perilla frutescens var. acuta) on Adipocyte Differentiation and Mice Fed a High-fat Diet. J. Food Sci. 2018, 83, 2384-2393. [CrossRef]

124. Han, Y.; Jung, H.W.; Bae, H.S.; Kang, J.S.; Park, Y.K. The extract of Cinnamomum cassia twigs inhibits adipocyte differentiation via activation of the insulin signaling pathway in 3T3-L1 preadipocytes. Pharm. Biol. 2013, 51, 961-967. [CrossRef]

125. Woon, S.M.; Seng, Y.W.; Ling, A.P.K.; Chye, S.M.; Koh, R.Y. Anti-adipogenic effects of extracts of Ficus deltoidea var. deltoidea and var. angustifolia on 3T3-L1 adipocytes. J. Zhejiang Univ. Sci. B 2014, 15, $295-302$. [CrossRef]

126. Xie, J.; Wang, Y.; Jiang, W.-W.; Luo, X.-F.; Dai, T.-Y.; Peng, L.; Song, S.; Li, L.-F.; Tao, L.; Shi, C.-Y.; et al. Moringa oleifera Leaf Petroleum Ether Extract Inhibits Lipogenesis by Activating the AMPK Signaling Pathway. Front. Pharmacol. 2018, 9, 1447. [CrossRef]

127. Velusami, C.C.; Agarwal, A.; Mookambeswaran, V. Effect of nelumbo nucifera petal extracts on lipase, adipogenesis, adipolysis, and central receptors of obesity. Evid. Based Complement. Altern. Med. 2013, 2013, 145925.

128. Ahn, J.H.; Kim, E.S.; Lee, C.; Kim, S.; Cho, S.H.; Hwang, B.Y.; Lee, M.K. Chemical constituents from Nelumbo nucifera leaves and their anti-obesity effects. Bioorganic Med. Chem. Lett. 2013, 23, 3604-3608. [CrossRef]

129. Saji, J.A.; Veena, R. An In vitro Approach to Evaluate the Anti Adipogenesis Activity of Passiflora edulis $\mathrm{f}$ Flavicarpa Degener Leaf Extracts in 3T3-L1 Cell Lines. J. Clin. Exp. Pharmacol. 2018, 8, 5.

130. Yang, J.H.; Choi, M.H.; Yang, S.H.; Cho, S.S.; Park, S.J.; Shin, H.J.; Ki, S.H. Potent Anti-Inflammatory and Antiadipogenic Properties of Bamboo (Sasa coreana Nakai) Leaves Extract and Its Major Constituent Flavonoids. J. Agric. Food Chem. 2017, 65, 6665-6673. [CrossRef]

131. Chaiittianan, R.; Sutthanut, K.; Rattanathongkom, A. Purple corn silk: A potential anti-obesity agent with inhibition on adipogenesis and induction on lipolysis and apoptosis in adipocytes. J. Ethnopharmacol. 2017, 201, 9-16. [CrossRef]

132. Ha, D.T.; Nam Trung, T.; Bich Thu, N.; Van On, T.; Hai Nam, N.; Van Men, C.; Thi Phuong, T.; Bae, K.H. Adlay seed extract (Coix lachryma-jobi L.) decreased adipocyte differentiation and increased glucose uptake in 3T3-L1 cells. J. Med. Food 2010, 13, 1331-1339. [CrossRef] 
133. Kim, H.L.; Sim, J.E.; Choi, H.M.; Choi, I.Y.; Jeong, M.Y.; Park, J.; Jung, Y.; Youn, D.H.; Cho, J.H.; Kim, J.H.; et al. The AMPK pathway mediates an anti-adipogenic effect of fruits of Hovenia dulcis Thunb. Food Funct. 2014, 5, 2961-2968. [CrossRef]

134. Duangjai, A.; Nuengchamnong, N.; Suphrom, N.; Trisat, K.; Limpeanchob, N.; Saokaew, S. Potential of coffee fruit extract and quinic acid on adipogenesis and lipolysis in 3T3-L1 adipocytes. Kobe J. Med. Sci. 2018, 64, E84-E92.

135. Da Silva Lima, N.; De Paula Numata, E.; De Souza Mesquita, L.M.; Dias, P.H.; Vilegas, W.; Gambero, A.; Ribeiro, M.L. Modulatory effects of guarana (Paullinia cupana) on adipogenesis. Nutrients 2017, 9, 635. [CrossRef]

136. Choi, E.H.; Lee, D.Y.; Park, H.S.; Shim, S.M. Changes in the profiling of bioactive components with the roasting process in Lycium chinense leaves and the anti-obesity effect of its bioaccessible fractions. J. Sci. Food Agric. 2019, 99, 4482-4492. [CrossRef]

137. Lowe, M.E. Structure and function of pancreatic lipase and colipase. Annu. Rev. Nutr. 1997, 17, 141-158. [CrossRef]

138. Bustanji, Y.; Mohammad, M.; Hudaib, M.; Tawaha, K.; Al-Masri, I.M.; AlKhatib, H.S.; Issa, A.; Alali, F.Q. Screening of some medicinal plants for their pancreatic lipase inhibitory potential. Jordan J. Pharm. Sci. 2011, 4, 81-88.

139. Drew, B.S.; Dixon, A.F.; Dixon, J.B. Obesity management: Update on orlistat. Vasc. Health Risk Manag. 2007, 3, 817-821.

140. Fei, H.; Li, M.; Liu, W.; Sun, L.; Li, N.; Cao, L.; Meng, Z.; Huang, W.; Ding, G.; Wang, Z.; et al. Potential lipase inhibitors from Chinese medicinal herbs. Pharm. Biol. 2016, 54, 2845-2850. [CrossRef]

141. Dechakhamphu, A.; Wongchum, N. Screening for anti-pancreatic lipase properties of 28 traditional Thai medicinal herbs. Asian Pac. J. Trop. Biomed. 2015, 5, 1042-1045. [CrossRef]

142. Abdul Rahman, H.; Saari, N.; Abas, F.; Ismail, A.; Mumtaz, M.W.; Abdul Hamid, A. Anti-obesity and antioxidant activities of selected medicinal plants and phytochemical profiling of bioactive compounds. Int. J. Food Prop. 2017, 20, 2616-2629. [CrossRef]

143. Marrelli, M.; Morrone, F.; Gambacorta, L.; Argentieri, M.P.; Conforti, F.; Avato, P. Phytochemical and biological profile of Moricandia arvensis (L.) DC.: An inhibitor of pancreatic lipase. Molecules 2018, 23, 2829. [CrossRef]

144. Rani, N.; Vasudeva, N.; Sharma, S.K. Quality assessment and anti-obesity activity of Stellaria media (Linn.) Vill. BMC Complement. Altern. Med. 2012, 12, 145. [CrossRef]

145. Conforti, F.; Perri, V.; Menichini, F.; Marrelli, M.; Uzunov, D.; Statti, G.A.; Menichini, F. Wild mediterranean dietary plants as inhibitors of pancreatic lipase. Phyther. Res. 2012, 26, 600-604. [CrossRef]

146. Adnyana, I.K.; Abuzaid, A.S.; Iskandar, E.Y.; Kurniati, N.F. Pancreatic lipase and $\alpha$-amylase inhibitory potential of mangosteen (Garcinia Mangostana Linn.) pericarp extract. Int. J. Med. Res. Health. Sci. 2016, 5, 23-28. [CrossRef]

147. Chanda, J.; Mukherjee, P.K.; Biswas, R.; Malakar, D.; Pillai, M. Study of pancreatic lipase inhibition kinetics and LC-QTOF-MS-based identification of bioactive constituents of Momordica charantia fruits. Biomed. Chromatogr. 2019, 33, e4463. [CrossRef]

148. Kim, G.N.; Shin, M.R.; Shin, S.H.; Lee, A.R.; Lee, J.Y.; Seo, B.I.; Kim, M.Y.; Kim, T.H.; Noh, J.S.; Rhee, M.H.; et al. Study of Antiobesity Effect through Inhibition of Pancreatic Lipase Activity of Diospyros kaki Fruit and Citrus unshiu Peel. Biomed. Res. Int. 2016, 2016, 1723042. [CrossRef]

149. Abd Rahman, R.N.Z.R. Anti-obesity Potential of Selected Tropical Plants via Pancreatic Lipase Inhibition. Adv. Obes. Weight Manag. Control. 2017, 6, 00163. [CrossRef]

150. Loizzo, M.R.; Marrelli, M.; Pugliese, A.; Conforti, F.; Nadjafi, F.; Menichini, F.; Tundis, R. Crocus cancellatus subsp. damascenus stigmas: Chemical profile, and inhibition of amylase, glucosidase and lipase, key enzymes related to type 2 diabetes and obesity. J. Enzyme Inhib. Med. Chem. 2016, 31, 212-218. [CrossRef]

151. Casacchia, T.; Sofo, A.; Casaburi, I.; Marrelli, M.; Conforti, F.; Statti, G.A. Antioxidant, enzyme-inhibitory and antitumor activity of the wild dietary plant Muscari comosum (L.) Mill. Int. J. Plant. Biol. 2017, 8, 6895. [CrossRef]

152. Teixeira, L.S.; Lima, A.S.; Boleti, A.P.A.; Lima, A.A.N.; Libório, S.T.; De Paula, L.; Oliveira, M.I.B.; Lima, E.F.; Costa, G.M.; Reginatto, F.H.; et al. Effects of Passiflora nitida Kunth leaf extract on digestive enzymes and high caloric diet in rats. J. Nat. Med. 2014, 68, 316-325. [CrossRef] 
153. Spínola, V.; Pinto, J.; Llorent-Martínez, E.J.; Tomás, H.; Castilho, P.C. Evaluation of Rubus grandifolius L. (wild blackberries) activities targeting management of type-2 diabetes and obesity using in vitro models. Food Chem. Toxicol. 2019, 123, 443-452. [CrossRef]

154. Marrelli, M.; Menichini, F.; Conforti, F. Hypolipidemic and Antioxidant Properties of Hot Pepper Flower (Capsicum annuum L.). Plant. Foods Hum. Nutr. 2016, 71, 301-306. [CrossRef]

155. Mnafgui, K.; Hamden, K.; Ben Salah, H.; Kchaou, M.; Nasri, M.; Slama, S.; Derbali, F.; Allouche, N.; Elfeki, A. Inhibitory activities of Zygophyllum album: A natural weight-lowering plant on key enzymes in high-fat diet-fed rats. Evid. Based Complement. Altern. Med. 2012, 2012, 620384. [CrossRef]

156. Rahman, M.M.; Kim, M.J.; Kim, J.H.; Kim, S.H.; Go, H.K.; Kweon, M.H.; Kim, D.H. Desalted Salicornia europaea powder and its active constituent, trans-ferulic acid, exert anti-obesity effects by suppressing adipogenic-related factors. Pharm. Biol. 2018, 56, 183-191. [CrossRef]

157. Sung, Y.Y.; Kim, D.S.; Kim, S.H.; Kim, H.K. Aqueous and ethanolic extracts of welsh onion, Allium fistulosum, attenuate high-fat diet-induced obesity. BMC Complement. Altern. Med. 2018, 18, 105. [CrossRef]

158. Jabri, M.A.; Sakly, M.; Marzouki, L.; Sebai, H. Chamomile (Matricaria recutita L.) decoction extract inhibits in vitro intestinal glucose absorption and attenuates high fat diet-induced lipotoxicity and oxidative stress. Biomed. Pharmacother. 2017, 87, 153-159. [CrossRef]

159. Wang, Y.P.; Wat, E.; Koon, C.M.; Wong, C.W.; Cheung, D.W.S.; Leung, P.C.; Zhao, Q.S.; Fung, K.P.; Lau, C.B.S. The beneficial potential of polyphenol-enriched fraction from Erigerontis Herba on metabolic syndrome. J. Ethnopharmacol. 2016, 187, 94-103. [CrossRef]

160. Choi, Y.; Yanagawa, Y.; Kim, S.; Whang, W.K.; Park, T. Artemisia iwayomogi extract attenuates high-fat diet-induced obesity by decreasing the expression of genes associated with adipogenesis in mice. Evid. Based Complement. Altern. Med. 2013, 2013, 915953.

161. Lee, H.M.; Yang, G.; Ahn, T.G.; Kim, M.D.; Nugroho, A.; Park, H.J.; Lee, K.T.; Park, W.; An, H.J. Antiadipogenic effects of aster glehni extract: In vivo and in vitro effects. Evid. Based Complement. Altern. Med. 2013, 2013, 859624. [CrossRef]

162. Gwon, S.Y.; Ahn, J.Y.; Chung, C.H.; Moon, B.; Ha, T.Y. Lithospermum erythrorhizon suppresses high-fat diet-induced obesity, and acetylshikonin, a main compound of lithospermum erythrorhizon, inhibits adipocyte differentiation. J. Agric. Food Chem. 2012, 60, 9089-9096. [CrossRef]

163. Mahesh Kumar, P.; Venkataranganna, M.V.; Manjunath, K.; Viswanatha, G.L.; Ashok, G. Momordica cymbalaria fruit extract attenuates high-fat dietinduced obesity and diabetes in C57BL/6 mice. Iran. J. Basic Med. Sci. 2018, 21, 1083-1090.

164. Jeong, E.J.; Jegal, J.; Ahn, J.; Kim, J.; Yang, M.H. Anti-obesity effect of Dioscorea oppositifolia extract in high-fat diet-induced obese mice and its chemical characterization. Biol. Pharm. Bull. 2016, 39, 409-414. [CrossRef]

165. Peixoto, T.C.; Moura, E.G.; de Oliveira, E.; Soares, P.N.; Guarda, D.S.; Bernardino, D.N.; Ai, X.X.; da ST Rodrigues, V.; de Souza, G.R.; da Silva, A.J.R.; et al. Cranberry (Vaccinium macrocarpon) extract treatment improves triglyceridemia, liver cholesterol, liver steatosis, oxidative damage and corticosteronemia in rats rendered obese by high fat diet. Eur. J. Nutr. 2018, 57, 1829-1844. [CrossRef]

166. Seyedan, A.; Alshawsh, M.A.; Alshagga, M.A.; Mohamed, Z. Antiobesity and Lipid Lowering Effects of Orthosiphon stamineus in High-Fat Diet-Induced Obese Mice. Planta Med. 2017, 83, 684-692. [CrossRef]

167. Tzeng, T.F.; Lu, H.J.; Liou, S.S.; Chang, C.J.; Liu, I.M. Reduction of lipid accumulation in white adipose tissues by Cassia tora (Leguminosae) seed extract is associated with AMPK activation. Food Chem. 2013, 136, 1086-1094. [CrossRef]

168. Lei, F.; Zhang, X.N.; Wang, W.; Xing, D.M.; Xie, W.D.; Su, H.; Du, L.J. Evidence of anti-obesity effects of the pomegranate leaf extract in high-fat diet induced obese mice. Int. J. Obes. 2007, 31, 1023-1029. [CrossRef]

169. Retnasamy, G.; Adikay, S. Effect of Hiptage madablota Gaertn. on high fat diet-Induced obese rats. Jordan J. Biol. Sci. 2014, 7, 113-118. [CrossRef]

170. Yimam, M.; Jiao, P.; Hong, M.; Brownell, L.; Lee, Y.C.; Kim, H.J.; Nam, J.B.; Kim, M.R.; Jia, Q. Morus alba, a Medicinal Plant for Appetite Suppression and Weight Loss. J. Med. Food 2019, 22, 741-751. [CrossRef]

171. Peng, C.H.; Lin, H.T.; Chung, D.J.; Huang, C.N.; Wang, C.J. Mulberry Leaf Extracts prevent obesity-induced NAFLD with regulating adipocytokines, inflammation and oxidative stress. J. Food Drug Anal. 2018, 26, 778-787. [CrossRef] 
172. Lim, H.H.; Lee, S.O.; Kim, S.Y.; Yang, S.J.; Lim, Y. Anti-inflammatory and antiobesity effects of mulberry leaf and fruit extract on high fat diet-induced obesity. Exp. Biol. Med. 2013, 238, 1160-1169. [CrossRef]

173. You, J.S.; Lee, Y.J.; Kim, K.S.; Kim, S.H.; Chang, K.J. Anti-obesity and hypolipidaemic effects of Nelumbo nucifera seed ethanol extract in human pre-adipocytes and rats fed a high-fat diet. J. Sci. Food Agric. 2014, 94, 568-575. [CrossRef]

174. Liu, S.; Li, D.; Huang, B.; Chen, Y.; Lu, X.; Wang, Y. Inhibition of pancreatic lipase, $\alpha$-glucosidase, $\alpha$-amylase, and hypolipidemic effects of the total flavonoids from Nelumbo nucifera leaves. J. Ethnopharmacol. 2013, 149, 263-269. [CrossRef]

175. Shen, Y.; Song, S.J.; Keum, N.; Park, T. Olive leaf extract attenuates obesity in high-fat diet-fed mice by modulating the expression of molecules involved in adipogenesis and thermogenesis. Evid. Based Complement. Altern. Med. 2014, 2014, 971890. [CrossRef]

176. Kim, N.-H.; Heo, J.-D.; Rho, J.-R.; Yang, M.H.; Jeong, E.J. Anti-obesity Effect of Halophyte Crop, Limonium tetragonum in High-Fat Diet-Induced Obese Mice and 3T3-L1 Adipocytes. Biol. Pharm. Bull. 2017, 40, 1856-1865. [CrossRef]

177. Jambocus, N.G.S.; Ismail, A.; Khatib, A.; Mahomoodally, F.; Saari, N.; Mumtaz, M.W.; Hamid, A.A. Morinda citrifolia L. leaf extract prevent weight gain in Sprague-Dawley rats fed a high fat diet. Food Nutr. Res. 2017, 61, 1338919. [CrossRef]

178. Karmase, A.; Birari, R.; Bhutani, K.K. Evaluation of anti-obesity effect of Aegle marmelos leaves. Phytomedicine 2013, 20, 805-812. [CrossRef]

179. Chung, A.P.Y.S.; Gurtu, S.; Chakravarthi, S.; Moorthy, M.; Palanisamy, U.D. Geraniin Protects High-Fat Diet-Induced Oxidative Stress in Sprague Dawley Rats. Front. Nutr. 2018, 5, 17. [CrossRef]

180. Chen, Q.; Wu, X.; Liu, L.; Shen, J. Polyphenol-rich extracts from Oiltea camellia prevent weight gain in obese mice fed a high-fat diet and slowed the accumulation of triacylglycerols in 3T3-L1 adipocytes. J. Funct. Foods 2014, 9, 148-155. [CrossRef]

181. Jung, C.H.; Jang, S.J.; Ahn, J.; Gwon, S.Y.; Jeon, T.I.; Kim, T.W.; Ha, T.Y. Alpinia officinarum Inhibits Adipocyte Differentiation and High-Fat Diet-Induced Obesity in Mice Through Regulation of Adipogenesis and Lipogenesis. J. Med. Food 2012, 15, 959-967. [CrossRef]

182. Grove, K.A.; Lambert, J.D. Laboratory, Epidemiological, and Human Intervention Studies Show That Tea (Camellia sinensis) May Be Useful in the Prevention of Obesity. J. Nutr. 2010, 140, 446-453. [CrossRef]

183. Basu, A.; Sanchez, K.; Leyva, M.J.; Wu, M.; Betts, N.M.; Aston, C.E.; Lyons, T.J. Green tea supplementation affects body weight, lipids, and lipid peroxidation in obese subjects with metabolic syndrome. J. Am. Coll. Nutr. 2010, 29, 31-40. [CrossRef]

184. Naderi Nabi, B.; Sedighinejad, A.; Haghighi, M.; Farzi, F.; Rimaz, S.; Atrkarroushan, Z.; Biazar, G. The Anti-Obesity Effects of Green Tea: A Controlled, Randomized, Clinical Trial. Iran. Red Crescent Med. J. 2018, 20, e55950. [CrossRef]

185. Riaz, G.; Chopra, R. A review on phytochemistry and therapeutic uses of Hibiscus sabdariffa L. Biomed. Pharmacother. 2018, 102, 575-586. [CrossRef]

186. Chang, H.C.; Peng, C.H.; Yeh, D.M.; Kao, E.S.; Wang, C.J. Hibiscus sabdariffa extract inhibits obesity and fat accumulation, and improves liver steatosis in humans. Food Funct. 2014, 5, 734-739. [CrossRef]

187. Blair, M.W.; Soler, A.; Cortés, A.J. Diversification and Population Structure in Common Beans (Phaseolus vulgaris L.). PLoS ONE 2012, 7, e49488. [CrossRef]

188. Celleno, L.; Tolaini, M.V.; D’Amore, A.; Perricone, N.V.; Preuss, H.G. A dietary supplement containing standardized Phaseolus vulgaris extract influences body composition of overweight men and women. Int. J. Med. Sci. 2007, 4, 45-52. [CrossRef]

189. Wu, X.; Xu, X.; Shen, J.; Perricone, N.V.; Preuss, H.G. Enhanced weight loss from a dietary supplement containing standardized Phaseolus vulgaris extract in overweight men and women. J. Appl. Res. 2010, 10, 73-79.

190. Ahmad, A.; Husain, A.; Mujeeb, M.; Khan, S.A.; Najmi, A.K.; Siddique, N.A.; Damanhouri, Z.A.; Anwar, F. A review on therapeutic potential of Nigella sativa: A miracle herb. Asian Pac. J. Trop. Biomed. 2013, 3, 337-352. [CrossRef]

191. Datau, E.A.; Wardhana; Surachmanto, E.E.; Pandelaki, K.; Langi, J.A. Fias Efficacy of Nigella sativa on serum free testosterone and metabolic disturbances in central obese male. Acta Med. Indones. 2010, 42, 130-134. 
192. Park, S.H.; Huh, T.L.; Kim, S.Y.; Oh, M.R.; Tirupathi Pichiah, P.B.; Chae, S.W.; Cha, Y.S. Antiobesity effect of Gynostemma pentaphyllum extract (actiponin): A randomized, double-blind, placebo-controlled trial. Obesity 2014, 22, 63-71. [CrossRef]

193. Lee, M.H.; Han, A.R.; Jang, M.; Choi, H.K.; Lee, S.Y.; Kim, K.T.; Lim, T.G. Antiskin inflammatory activity of black ginger (Kaempferia parviflora) through antioxidative activity. Oxid. Med. Cell. Longev. 2018, 2018, 5967150. [CrossRef]

194. Yoshino, S.; Awa, R.; Miyake, Y.; Fukuhara, I.; Sato, H.; Ashino, T.; Tomita, S.; Kuwahara, H. Daily intake of Kaempferia parviflora extract decreases abdominal fat in overweight and preobese subjects: A randomized, double-blind, placebo-controlled clinical study. Diabetes Metab. Syndr. Obes. 2018, 11, 447-458. [CrossRef]

195. Johri, R. Cuminum cyminum and Carum carvi: An update. Pharmacogn. Rev. 2011, 5, 63-72. [CrossRef]

196. Sawangiit, R.; Puttarak, P.; Saokaew, S.; Chaiyakunapruk, N. Efficacy and Safety of Cissus quadrangularis L. in Clinical Use: A Systematic Review and Meta-analysis of Randomized Controlled Trials. Phyther. Res. 2017, 31, 555-567. [CrossRef]

197. Oben, J.; Kuate, D.; Agbor, G.; Momo, C.; Talla, X. The use of a Cissus quadrangularis formulation in the management of weight loss and metabolic syndrome. Lipids Health Dis. 2006, 5, 24. [CrossRef]

198. Ebrahimi, S.; Mollaei, H.; Hoshyar, R. Ziziphus Jujube: A review study of its anticancer effects in various tumor models invitro and invivo. Cell. Mol. Biol. 2017, 63, 122-127. [CrossRef]

199. Mostafa, U.E.S.; Labban, L. The effect of zizyphus jujube on serum lipid profile and some anthropometric measurements. Pakistan J. Nutr. 2013, 12, 538-543. [CrossRef]

200. Scalbert, A.; Johnson, I.T.; Saltmarsh, M. Polyphenols Antioxidants and Beyond. Am. J. Clin. Nutr. 2005, 81, 215S-217S. [CrossRef]

201. Palikaras, K.; Lionaki, E.; Tavernarakis, N. Balancing mitochondrial biogenesis and mitophagy to maintain energy metabolism homeostasis. Cell Death Differ. 2015, 22, 1399-1401. [CrossRef]

202. Dos Santos, T.W.; Pereira, Q.C.; Teixeira, L.; Gambero, A.; Villena, J.A.; Ribeiro, M.L. Effects of polyphenols on thermogenesis and mitochondrial biogenesis. Int. J. Mol. Sci. 2018, 19, 2757. [CrossRef]

203. Qiu, H.; Schlegel, V. Impact of nutrient overload on metabolic homeostasis. Nutr. Rev. 2018, 76, 693-707. [CrossRef]

204. Yahfoufi, N.; Alsadi, N.; Jambi, M.; Matar, C. The immunomodulatory and anti-inflammatory role of polyphenols. Nutrients 2018, 10, 1618. [CrossRef]

205. Pourreza, N. Phenolic compounds as potential antioxidant. Jundishapur J. Nat. Pharm. Prod. 2013, 8, 149-150. [CrossRef] [PubMed]

206. Samodien, E.; Johnson, R.; Pheiffer, C.; Mabasa, L.; Erasmus, M.; Louw, J.; Chellan, N. Diet-induced hypothalamic dysfunction and metabolic disease, and the therapeutic potential of polyphenols. Mol. Metab. 2019, 27, 1-10. [CrossRef] [PubMed]

(C) 2019 by the authors. Licensee MDPI, Basel, Switzerland. This article is an open access article distributed under the terms and conditions of the Creative Commons Attribution (CC BY) license (http://creativecommons.org/licenses/by/4.0/). 